\title{
Leguminosae-Papilionoideae na Serra do Cabral, MG, Brasil
}

\author{
Edson Dias da Silva ${ }^{1,2}$ e Angela Borges Martins ${ }^{1}$
}

Recebido: 19.08.2010; aceito: 28.03.2013

\begin{abstract}
Leguminosae-Papilionoideae in the Serra do Cabral, Minas Gerais State, Brazil). A floristic survey of the Papilionoideae in the Serra do Cabral is presented. The region is part of a mountain range belonging to the Cadeia do Espinhaço, located between latitudes $17^{\circ} 18^{\prime}-18^{\circ} 06^{\prime} \mathrm{S}$ and longitudes $44^{\circ} 43^{\prime}-44^{\circ} 10^{\prime} \mathrm{W}$, with altitudes from 515 to $1,400 \mathrm{~m}$, where the predominant formations are Cerrado and Campos Rupestres. The subfamily is represented in the area by 12 tribes, 34 genera and 62 species. Twenty five species occur only in Brazil, six are endemic to Minas Gerais State and 17 are restricted to Cerrado. The restricted distribution of most species found suggests that the taxa grows only on specific phytophysiognomies and are dependent of the preservation of these habitats for survival. A list of genera and species, with their respective identification keys, data on the geographical distribution and the phytogeographic domains where species occur are presented.
\end{abstract}

Key words: Campos Rupestres, Cerrado, Fabaceae, floristic survey

RESUMO - (Leguminosae-Papilionoideae na Serra do Cabral, MG, Brasil). É apresentado um levantamento das Papilionoideae da Serra do Cabral. A região faz parte da Cadeia do Espinhaço, estando localizada entre as latitudes $17^{\circ} 18^{\prime}-18^{\circ} 06^{\prime} \mathrm{S}$ e as longitudes $44^{\circ} 43^{\prime}-44^{\circ} 10^{\prime} \mathrm{W}$, com altitudes que variam de 515 a $1.400 \mathrm{~m}$, onde predominam formações de Cerrado e Campo Rupestre. A subfamília está representada na área por 12 tribos, 34 gêneros e 62 espécies. Vinte e cinco espécies só ocorrem no Brasil, seis são endêmicas do Estado de Minas Gerais e 17 estão restritas ao Cerrado. A distribuição restrita de grande parte das espécies encontradas sugere que esses táxons desenvolvem-se apenas em fitofisionomias específicas sendo, portanto, dependentes da preservação desses ambientes para a sobrevivência. Além de uma lista de gêneros e espécies, com suas respectivas chaves de identificação, também são apresentados dados de distribuição geográfica e os domínios fitogeográficos nos quais as espécies ocorrem.

Palavras-chave: Campos Rupestres, Cerrado, Fabaceae, levantamento florístico

\section{Introdução}

A família Leguminosae (= Fabaceae) é constituída por 727 gêneros e 19.327 espécies (Lewis et al. 2005) sendo a terceira maior família de Angiospermas. Papilionoideae é a maior das três subfamílias com cerca de dois terços de todos os gêneros e espécies (Lewis et al. 2005). Constituída por 28 tribos, 478 gêneros e 13.800 espécies, a subfamília constitui um grupo monofilético (Wojciechowski 2003, Lewis et al. 2005).

A Serra do Cabral ocupa área de aproximadamente $2.500 \mathrm{~km}^{2}$ em que predominam as fisionomias de Cerrado sensu lato: Campo Limpo, Campo Sujo, Campo Cerrado, Cerrado sensu stricto e Cerradão, de acordo com a classificação de Eiten $(1972,1983)$ e os Campos Rupestres, no alto da serra, em altitudes acima de 900 m (Menezes \& Giulietti 1986).
As leguminosas estão bem adaptadas à primeira colonização e exploração de diversos ambientes devido, em parte, às suas associações com bactérias fixadoras de nitrogênio ou com ectomicorrizas (Lewis 1987). Bactérias do gênero Rhizobium, localizadas em nódulos radiculares encontrados em muitas espécies, convertem o nitrogênio atmosférico em amônia, forma solúvel que pode ser utilizada por outros vegetais, e tais leguminosas são, assim, extremamente valiosas como adubos naturais (Lewis 1987).

Entre os estudos realizados em Cerrado e Campo Rupestre, que apontam a importância da família Leguminosae em suas composições florísticas, pode-se destacar os realizados em Lagoa Santa-MG (Warming \& Ferri 1973), em Mucugê-BA (Harley \& Simmons 1986), na Serra do Cipó-MG (Giulietti et al. 1987),

1. Universidade Estadual de Campinas, Instituto de Biologia, Departamento de Botânica, Caixa Postal 6109, 13083-970 Campinas, SP, Brasil

2. Autor para correspondência: edsonxv@gmail.com 
em Mogi Guaçu-SP (Mantovani \& Martins 1993), no Pico das Almas-BA (Lewis 1995), na Chapada dos Veadeiros-GO (Munhoz \& Proença 1998), no Parque Nacional das Emas-GO (Batalha 2001), em Catolés-BA (Zappi et al. 2003) e em Grão Mogol-MG (Queiroz 2004).

Dados da Fundação Biodiversitas (Drummond 2008) indicam que 29 espécies de leguminosas correm o risco de desaparecer do domínio dos Cerrados, sendo 23 dessas restritas aos Campos Rupestres. Inventários florísticos e estudos fitossociológicos realizados em várias regiões do Brasil já estão oferecendo evidências da importância de Leguminosae na composição e estrutura de vários tipos de biomas. No entanto, a situação atual do conhecimento científico a respeito dessas plantas no neotrópico é pouco satisfatória em comparação com o nível atingido pelos estudos da família tanto na África como na Ásia (Lewis 1987). O presente trabalho tem como objetivo apresentar o levantamento das espécies de Papilionoideae na Serra do Cabral, Minas Gerais.

\section{Material e métodos}

A Serra do Cabral está localizada na região centro-norte do Estado de Minas Gerais nos municípios de Francisco Dumont $\left(17^{\circ} 18^{\prime} \mathrm{S}\right.$ e $\left.44^{\circ} 14^{\prime} \mathrm{W}\right)$, Augusto de Lima $\left(18^{\circ} 06^{\prime} \mathrm{S}\right.$ e $\left.44^{\circ} 16^{\prime} \mathrm{W}\right)$, Lassance $\left(17^{\circ} 18^{\prime} \mathrm{S}\right.$ e $\left.44^{\circ} 34^{\prime} \mathrm{W}\right)$, Várzea de Palma $\left(17^{\circ} 35^{\prime} \mathrm{S}\right.$ e $\left.44^{\circ} 43^{\prime} \mathrm{W}\right)$, Buenópolis $\left(17^{\circ} 35^{\prime} \mathrm{S}\right.$ e $\left.44^{\circ} 10^{\prime} \mathrm{W}\right)$ e Joaquim Felício $\left(17^{\circ} 45^{\prime} \mathrm{S} 44^{\circ} 10^{\prime} \mathrm{W}\right)$. Sua área é de aproximadamente $2.500 \mathrm{~km}^{2}$, com extenção de $100 \mathrm{~km}$ na direção norte-sul e 15 a $35 \mathrm{~km}$ na direção leste-oeste. Inserida na Bacia do São Francisco, a Serra do Cabral faz parte da unidade litoestratigráfica Supergrupo Espinhaço, de idade Paleo/mesoproterozóica (Renger \& Almeida-Abreu 2000, Alkmim \& Martins Neto 2001). No alto da serra, onde afloram os quartzitos da Formação Galho de Miguel, dominam planaltos que atingem de 900 a $1.200 \mathrm{~m}$ e cumes que podem chegar a $1.400 \mathrm{~m}$ de altitude (Viveiros \& Walde 1976). O clima é mesotérmico (Cwb de Köppen 1931), com verões moderados, estação chuvosa no verão e seca no inverno, com temperaturas anuais médias entre 17,4 e $19,8^{\circ} \mathrm{C}$. O índice pluviométrico em Lassance é de $1.148,1 \mathrm{~mm}$ anuais, com maior concentração das chuvas de novembro a janeiro (Patrus et al. 2001).

Para o estudo das Papilionoideae da Serra do Cabral foram realizadas coletas a cada dois meses, entre 2003 e 2004. Além das amostras coletadas durante as expedições, também foram estudadas as coleções dos herbários UEC, SPF, SP, ESA, RB, BHCB e MBM. As siglas dos herbários estão de acordo com Holmgren et al. (1990). Todo o material testemunho está depositado no herbário UEC. Os dados de distribuição geográfica e domínios fitogeográficos são resultados da coleta de informações contidas em revisões e teses, material de herbário e sites que contenham essas informações como a Lista de Espécies da Flora do Brasil (2013) e o Species link (2012).

\section{Resultados e Discussão}

\section{Papilionoideae DC.}

Ervas, subarbustos, arbustos, lianas ou árvores. Folhas pinadas, geralmente trifolioladas, ocasionalmente unifolioladas ou simples. Flores zigomorfas. Cálice gamossépalo. Corola dialipétala composta por 5 pétalas; uma superior (vexilo ou estandarte) geralmente mais externa na antese; duas laterais (asas ou alas) e duas abaxiais (quilha ou carena), coalescentes ou livres. Sépalas unidas na base formando um tubo. Estames (9-)10- $\infty$, raramentes vistosos. Semente com cicatriz hilar, eixo radícula-hipocótilo geralmente infletido e pleurograma ausente.

\section{Chave para os gêneros de Papilionoideae da Serra do Cabral}

1. Corola não papilionácea (figura 1a) formada por 5 pétalas semelhantes entre si (figura 1 b), reduzida a uma pétala vexilar ou ausente (figura 1c)

2. Pecíolo e raque alados ou marginados; corola ausente ou com 1 pétala vexilar; estames dimorfos, mais de 10 (figura 1k), os maiores 2-11, com anteras oblongas, os menores ca. 100; anteras orbiculares Swartzia

2. Pecíolo e raque sem alas, não marginados; corola com 5 pétalas; estames 10, uniformes (figura 11); anteras orbiculares a elípticas

1. Corola papilionácea (figura 1d, e, f, g, h, i) formada por 5 pétalas, sendo pelo menos 3 diferentes entre si (figura $1 \mathrm{j}$ ) 
3. Estames livres entre si (figura $1 \mathrm{~m}$ ) ou levemente concrescidos na base

4. Folíolos com pontuações ou linhas translúcidas; anteras apiculadas (figura 1q); ovário uniovulado; fruto sâmara (figura 1r) Myroxylon

4. Folíolos sem pontuações ou linhas translúcidas; anteras sem apículo (figura $1 \mathrm{~m}$ ); ovário pluriovulado; legume samaróide (figura 1s) Bowdichia

3. Estames concrescidos em tubo (figura $1 \mathrm{n}, \mathrm{o}, \mathrm{p}$ ) ou bainha aberta

5. Estames com anteras dimorfas, as maiores basifixas e as menores dorsifixas (figura 1n) ou estames férteis alternando com estaminódios (figura 10)

6. Folhas 1-folioladas, 2-folioladas (figura 1t), 3-trifolioladas (figura 1u, v) ou 4-folioladas; cálice 5-lobado (figura 1w) ou 5-laciniado (figura 1x, y)

7. Fruto lomento (figura $2 \mathrm{~b}, \mathrm{c}$ )

8. Cálice tubuloso; lomento com 1-2-articulos (figura 2b); estípulas amplexicaules, bidentadas ..... Stylosanthes

8. Cálice não tubuloso; lomento com mais de 2 artículos; estípulas com outras características

9. Inflorescência em espiga; flores 2-bracteoladas; estípulas peltadas; estames com filetes de dois tamanhos; lomentos cerdosos (figura 2c), sem glândulas Zornia

9. Inflorescência em racemo; flores 1-bracteoladas ou sem bractéolas; estípulas não peltadas; estames com filetes quase do mesmo tamanho; lomentos sem cerdas, glandulosos

Poiretia

7. Fruto de outro tipo

10. Lianas robustas; raque da inflorescência com nodosidades conspícuas Dioclea

10. Ervas, subarbustos ou arbustos; raque da inflorescência sem nodosidades ou com nodosidades inconspícuas

11. Flores amarelas com estrias vináceas; vexilo 2-apendiculado na base (figura 1g); legume inflado (figura 2d) Crotalaria 11. Flores roxas; vexilo não apendiculado; legume subcompresso Lupinus

6. Folhas com mais de quatro folíolos (figura 1z); cálice bilabiado (figura 2a) Harpalyce

5. Estames com anteras uniformes (figura 1P); estaminódios ausentes

12. Folhas simples (figura 2e), 1-folioladas ou 3-folioladas (figura 2f)

13. Raque da inflorescência com nodosidades

14. Estilete barbado (figura $2 \mathrm{j}$ ); carena com ápice tubuloso (figura $2 \mathrm{k}, 1$ ), muito encurvado, às vezes torcida para o lado ou rostrada

15. Estípulas peltadas Vigna

15. Estípulas não peltadas

16. Pseudoracemos com nodosidades conspícuas; carena encurvada, frequentemente rostrada; estilete não dilatado no ápice; sementes 8-9 Oryxis

16. Pseudoracemos com nodosidades inconspícuas; carena torcida para o lado; estilete dilatado no ápice; sementes 2-22 Macroptilium

14. Estilete glabro ou com tricomas curtos, não barbado; carena com ápice não tubuloso (figura 2m), reta ou levemente encurvada, não torcida lateralmente, nem rostrada

17. Ovário longamente estipitado; cálice avermelhado, com lacínias menores que o tubo (figura 1e)

Camptosema

17. Ovário séssil ou subséssil; cálice não avermelhado, com lacínias maiores que o tubo (figura $2 \mathrm{n}$ )

18. Fruto internamente septado entre as sementes Calopogonium

18. Fruto não septado entre as sementes

19. Folhas pecioladas ou, se subsésseis, 1-folioladas; flores violáceas a rosadas; estame vexilar concrescido com os demais apenas na base .. Galactia

19. Folhas sésseis a subsésseis, 3-folioladas; flores vermelhas; estame vexilar concrescido com os demais até a metade do filete 
13. Raque da inflorescência sem nodosidades

20. Fruto lomento

Desmodium

20. Fruto de outro tipo

21. Folíolos glandulosos em ao menos uma das faces; vexilo com base auriculada; ovário 1-2-ovulado; sementes 1-2

22. Planta escandente; legume ovado a oblongo-elíptico, constrito ou marcado entre as sementes (figura 2o) Rhynchosia

22. Planta ereta a subereta; legume amplamente oblongo a orbicular, rombóide, compresso (figura 2p) Eriosema

21. Folíolos não glandulosos; vexilo com base não auriculada; ovário com mais de 2 óvulos; sementes mais de 2

23. Vexilo calcarado no dorso (figura 2q); fruto com margens espessas Centrosema

23. Vexilo não calcarado no dorso; fruto com margens não espessas 24. Vexilo com calo conspícuo na base; estames de dois tamanhos; estilete não barbado Periandra

24. Vexilo sem calo na base; estames iguais; estilete barbado Clitoria

12. Folhas pinadas, multifolioladas (figura $2 \mathrm{~g}, \mathrm{~h}, \mathrm{i}$ )

25. Ervas, subarbustos ou arbustos

26. Fruto do tipo lomento (figura 2 r) Aeschynomene

26. Fruto de outro tipo

27. Legume curto-cilíndrico; folíolos com tricomas malpiguiáceos Indigofera

27. Legume longo-compresso; folíolos sem tricomas malpiguiáceos Sesbania 25. Árvores

28. Fruto sâmara (figura $2 \mathrm{~s}, \mathrm{t}, \mathrm{u}$ ) ou legume samaróide (figura 2v)

29. Sâmara com ala basal (figura $2 \mathrm{~s}$ )

Platypodium

29. Sâmara com ala apical (figura $2 \mathrm{t}, \mathrm{u}$ ) ou legume samaróide (figura $2 \mathrm{v}$ )

30. Legume samaróide com região seminífera mediana

31.Folíolos alternos (figura $2 \mathrm{~h}$ ); carena menor que as asas; fruto com nervuras marginais inconspícuas

Dalbergia

31. Folíolos opostos; carena igual ou maior que as asas; fruto com nervuras marginais proeminentes Lonchocarpus

30. Sâmara com ala apical

32. Sâmara calcarada, núcleo seminífero basal fortemente diferenciado da ala, equinado (figura $2 u$ ); cálice 4-laciniado (figura $2 x$ ); ovário giboso, glandular Centrolobium

32. Sâmara não calcarada, ala e núcleo seminífero pouco diferenciados, não equinado (figura 2T); cálice 5-laciniado, ovário não giboso, glândulas ausentes

Machaerium

28. Fruto drupáceo (figura 2Y) ou criptosâmara (figura 2W)

33. Fruto drupáceo, globoso (figura $2 \mathrm{Y}$ ); cálice campanulado a subturbinado, com

5 lacínias iguais, sem glândulas .... Andira

33. Fruto criptosâmara (figura $2 \mathrm{~W}$ ); cálice com tubo curto, com 2 lacínias

superiores em forma de asa e as demais curtas, glandulares (figura 2Z) Pterodon

\section{Aeschynomene L., Sp. Pl. 2: 713. 1753.}

Ervas, subarbustos ou arbustos, raramente pequenas árvores. Folhas pinadas com 5-80 folíolos, unifolioladas, raro reduzidas a acículos ou folhas modificadas em escamas. Flores amarelo-alaranjadas, raro lilases ou violáceas. Androceu monadelfo com 10 estames, ou diadelfo com estames concrescidos em tubo aberto de $5+5$. Anteras uniformes. Lomento com 1-18 artículos.

Gênero pertencente à tribo Dalbergieae Bronn ex DC. com 175-180 espécies distribuídas pelas regiões tropicais e temperadas da América, África e Ásia (Fernandes 1996, Lewis et al. 2005). No Brasil estão registradas 52 espécies (Fernandes 1996). 
Chave para as espécies de Aeschynomene da Serra do Cabral

1. Lomento 1-3-articulado, reflexo ou quase; ramos fortemente híspidos a hirsuto-viscosos. 2. Estípite do lomento com 1-2 mm compr., com tricomas de 2-4 mm compr., tricomas agrupados abaixo do artículo basal A. histrix var. histrix

2. Estípite do lomento com 2-8 mm compr., com tricomas de $1 \mathrm{~mm}$ compr., sem tricomas agrupados abaixo do artículo basal 3. Estípite do lomento com ca. $2 \mathrm{~mm}$ compr.; folhas 9-11-folioladas; folíolos 0,9-1,2 cm compr., iguais ao longo de toda folha; ovário piloso, artículos híspido-glandulosos ... A. brasiliana var. brasiliana 3. Estípite do lomento 2-8 mm compr.; folhas 31-folioladas; folíolos diminuindo de tamanho em direção ao ápice, 4,3-8,5mmcompr.;ovárioglabro; artículos glabros a pubescentes, desprovidos de glândulas

1. Lomento (3-)4-13-articulado, não reflexo; ramos glabros, adpresso-pilosos, estrigosos ou levemente híspidos, lomento sempre com mais de 5 artículos

4. Lomento com a margem superior reta e a inferior levemente ondulada, (6-)13-articulado, artículos subquadrangulares .. A. evenia

4. Lomento com a margem superior quase reta e a inferior conspicuamente ondulada, (3-)4-6-articulado, artículos semicirculares, elípticos, ovados ou suborbiculares

5. Lomento com a margem superior quase reta e a inferior ondulada, (3-)4-5articulado, artículos semicirculares, 5-6 × 3-4 mm; folíolos 6-15 mm compr. ....... A. marginata var. marginata

5. Lomento com as duas margens onduladas, 5-6-articulado, artículos suborbiculares, elípticos ou ovados, Ca. 3,5 × $2 \mathrm{~mm}$; folíolo 3-5 $\mathrm{mm}$ compr. A. paniculata

1.1. Aeschynomene brasiliana (Poir.) DC. var. brasiliana, Prodr. 2: 322. 1825.

Material selecionado: BRASIL. Minas Gerais: Joaquim Felício, 8-VII-2004, fl., E.D. Silva et al. 301 (UEC).
1.2. Aeschynomene evenia $\mathbf{C}$. Wright ex Sauvalle, Anales Acad. Ci. Med. Habana 5: 334. 1868[1869].

Material selecionado: BRASIL. Minas Gerais: Joaquim Felício, Serra do Cabral, 11-III-1970, Irwin et al. 27407 (RB, SP); idem, 8-III-1970, Irwin et al. 27192 (RB, SP).

1.3. Aeschynomene histrix Poir. var. histrix, Encycl. Suppl. 4: 77. 1816.

Material selecionado: BRASIL. Minas Gerais: Augusto de Lima, 9-IX-2003, fl., E.D. Silva et al. 121 (UEC); Joaquim Felício, Serra do Cabral, 14-III-1997, G. Hatschbach 66261 (MBM).

1.4. Aeschynomene marginata Benth. var. marginata, Fl. bras. 15(1): 66. 1859.

Material selecionado: BRASIL. Minas Gerais: Joaquim Felício, Serra do Cabral, 11-IX-2003, E.D. Silva et al. 161 (UEC); idem, 22-III-1994, C.M. Sakuragui et al. (ESA24825); idem,16-V-1999, V.C. Souza et al. 22556 (ESA); idem, 13-V-1997, P.E. Gibbs et al. 5022 (MBM).

1.5. Aeschynomene paniculata Willd. ex Vogel, Linnaea 12: 95. 1838.

Material selecionado: BRASIL. Minas Gerais: Augusto de Lima, 9-IX-2003, fl., E.D. Silva et al. 121 (UEC); Várzea de Palma, Serra do Cabral, 7-VII-2004, E.D. Silva et al. 286 (UEC); idem, 12-III-95, G. Hatschbach et al. 61774 (MBM); Joaquim Felício, Serra do Cabral, 19-III-1994, C.M. Sakuragui et al. s.n. (ESA24293).

1.6. Aeschynomene vogelii Rudd, Journ. Wash. Acad. Sci. 49(2): 48. 1959.

Material selecionado: BRASIL. Minas Gerais: Joaquim Felício, Serra do Cabral, 7-VII-2004, E.D. Silva et al. 259 (UEC); idem, 11-VII-2001, V.C. Souza et al 25448 (ESA); idem, 28-VII-1976, P.E. Gibbs et al. 2414 (UEC); idem, 13-V-1977, P.E. Gibbs et al. 5048 (UEC).

2. Andira Juss., nom. cons., Gen. Pl: 363. 1789.

Arbustos ou árvores. Folhas imparipinadas. Folíolos 1-17. Flores róseas ou violáceas. Cálice campanulado a subturbinado, 5-dentado. Androceu dialdelfo. Anteras uniformes. Ovário longo-estipitado. Óvulos 4, raro 1 ou 2. Estilete curto, encurvado. 

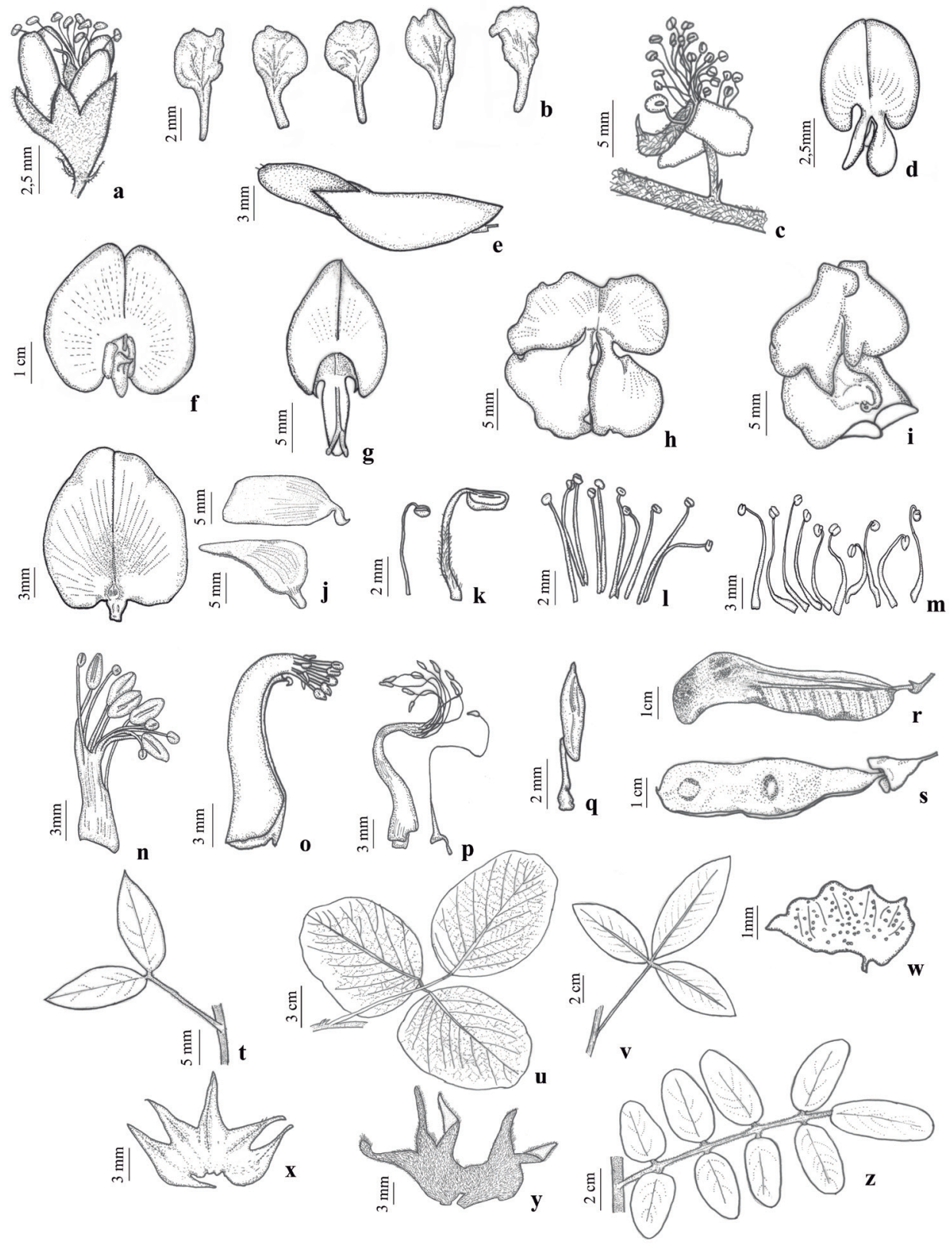

Figura 1. a. Leptolobium dasycarpum (Hatscbach 67174). b. Leptolobium brachystachyum (Rodrigues 294). c. Swartzia pilulifera (Silva 15). d. Aeschynomene marginata var. marginata (Silva 108). e. Camptosema cocineum var. coccineum (Silva 183). f. Centrosema venosum (Silva 203). g. Crotalaria maypurensis (Silva 67). h. Dioclea latifolia (Silva 71). i. Vigna peduncularis (Silva 185). j. Crotalaria maypurensis (Silva 115). k. Swartzia macrostachya (Laboriau \& Valio 1229). 1. Leptolobium dasycarpum (Hatschbach 67174). m. Bowdichia virgilioides (Silva 170). n. Crotalaria martiana subsp. mohlenbrockii (Silva 124). o. Dioclea latifolia (Silva 71). p. Vigna firmula (Silva 250). q e r. Myroxylon peruiferum (s.c. UEC11391). s. Bowdichia virgilioides (Silva 170). t. Zornia latifolia (Silva 194). u. Dioclea latifolia (Silva 71). v. Crotalaria micans (Silva 58). w. Poiretia punctata (Silva 62). x. Crotalaria maypurensis (Silva 115). y. Crotalaria martiana subsp. mohlenbrockii (Silva 124). z. Harpalyce brasiliana (Silva 99).

Figure 1. a. Leptolobium dasycarpum (Hatscbach 67174). b. Leptolobium brachystachyum (Rodrigues 294). c. Swartzia pilulifera (Silva 15). d. Aeschynomene marginata var. marginata (Silva 108). e. Camptosema cocineum var. coccineum (Silva 183). f. Centrosema venosum (Silva 203). g. Crotalaria maypurensis (Silva 67). h. Dioclea latifolia (Silva 71). i. Vigna peduncularis (Silva 185). j. Crotalaria maypurensis (Silva 115). k. Swartzia macrostachya (Laboriau \& Valio 1229). 1. Leptolobium dasycarpum (Hatschbach 67174). m. Bowdichia virgilioides (Silva 170). n. Crotalaria martiana subsp. mohlenbrockii (Silva 124). o. Dioclea latifolia (Silva 71). p. Vigna firmula (Silva 250). q e r. Myroxylon peruiferum (s.c. UEC11391). s. Bowdichia virgilioides (Silva 170). t. Zornia latifolia (Silva 194). u. Dioclea latifolia (Silva 71). v. Crotalaria micans (Silva 58). w. Poiretia punctata (Silva 62). x. Crotalaria maypurensis (Silva 115). y. Crotalaria martiana subsp. mohlenbrockii (Silva 124). z. Harpalyce brasiliana (Silva 99). 
Legume drupáceo, obovado ou ovado, globoso, levemente achatado. Semente única.

Gênero pertecente à tribo Dalbergieae Bronn ex DC. com 29 espécies distribuídas principalmente na região neotropical, com uma espécie na África (Pennington 2003).

2.1. Andira humilis Mart. ex Benth., Comm. Legum. Gen.: 45. 1837.

Material selecionado: BRASIL. Minas Gerais: Joaquim Felício, Serra do Cabral, 11-IX-2003, E.D. Silva et al. 155 (UEC); idem, 21-X-1999, G. Hatschbach 69394 (MBM); idem, 17-I-1996, G.M. Hatschbach 64265 (MBM, BHCB).

3. Bowdichia Kunth, Nov. Gen. 6: 376. 1823.

Árvores. Folhas imparipinadas. Flores azuis a brancas. Cálice turbinado-campanulado, encurvado, 5-dentado. Carena oblonga, livre, menor que as asas. Estames livres 10, algumas vezes desprovidos de anteras. Ovário estipitado, pluriovulado, com disco espessado. Legume samaróide, estreito-alado. Sementes 1 ou mais, oblongas.

Gênero sul americano pertecente à tribo Sophoreae Spreng ex DC. com duas espécies distribuídas pelo Brasil, Colômbia, Guyana, Suriname e Venezuela (Lewis et al. 2005).

3.1. Bowdichia virgilioides Kunth, Nov. Gen. 6: 376. 1823.

Material selecionado: BRASIL. Minas Gerais: Joaquim Felício, 9-IX-2003, E.D. Silva et al. 123 (UEC).

4. Calopogonium Desv., Ann. Sci. Nat. 9: 423. 1826.

Ervas ou subarbustos escandentes. Folhas trifolioladas. Folíolos rombóides, elípticos, ovais, oval-lanceolados ou assimétricos. Inflorescência racemosa, nodosa. Flores azuis ou violáceas. Estames 10, diadelfos, às vezes com 1 estaminódio. Anteras uniformes. Ovário pluriovulado. Legume deiscente, bivalvar, achatado, reto ou falcado, septado entre as sementes.

Gênero pertencente à tribo Phaseoleae Bronn ex DC. com 5-6 espécies nas Américas do Sul e Central, e uma única espécie na África e Ásia (Carvalho-Okano \& Leitão Filho 1985, Lewis et al. 2005).

4.1. Calopogonium caeruleum (Benth.) C. Wright, Anales Acad. Ci. Med. Habana 5: 337. 1868[1869].

Material selecionado: BRASIL. Minas Gerais: Serra do Cabral, 9-III-1970, Irwin et al. 27254 (RB, SP).
5. Camptosema Hook. \& Arn., Bot. Misc. 3: 200. 1823.

Arbustos a trepadeiras volúveis. Folhas simples, sésseis, 3-folioladas, ocasionalmente reduzidas a uma folha unifoliolada. Inflorescência nodosa. Flores 2,5-4 cm compr. Cálice vermelho, tubuloso, 4-laciniado, lacínias mais curtas que o tubo. Pétalas vermelhas. Vexilo alongado, elíptico, 2-auriculado. Androceu diadelfo. Anteras uniformes. Ovário estipitado. Óvulos 7-12. Legume linear.

Gênero pertencente à tribo Phaseoleae Bronn ex DC. com 10 espécies ocorrentes na América do Sul, principalmente no Brasil (Queiroz 1999, Lewis et al. 2005).

Chave para as espécies de Camptosema da Serra do Cabral

1. Folha simples, espesso-coriácea, base fortemente cordada; pecíolo 0,3-0,7 cm compr....... C. coccineum

2. Folha com face abaxial densamente serícea C. coccineum var. nitens

2. Folha esparsamente adpresso-piloso em ambas as faces, glabrescente ou raramente velutina C. coccineum var. coccineum

1. Folha 3-foliolada; folíolos estreito-coriáceos de base arredondada a subcordada; pecíolo 1,5-5,5 cm compr. C. coriaceum

5.1. Camptosema coccineum (Mart. ex Benth.) Benth. var. coccineum, Fl. bras. 15(1): 15. 1862.

Material selecionado: BRASIL. Minas Gerais: Joaquim Felício, Serra do Cabral, 8-XII-2003, E.D. Silva et al. 223 (UEC); idem, 16-V-1999, V.C. Souza et al. 22517 (ESA); idem, 13-IV-1977, P.E. Gibbs et al. 5026 (MBM).

5.2. Camptosema coccineum var. nitens (Benth.) Benth., Fl. bras. 15(1): 154. 1862.

Material selecionado: BRASIL. Minas Gerais: Augusto de Lima, Serra do Cabral, 9-IX-2003, E.D. Silva et al. 122 (UEC).

5.3. Camptosema coriaceum (Nees \& Mart.) Benth., Fl. bras. 15(1): 155. 1862.

Material selecionado: BRASIL. Minas Gerais: Joaquim Felício, Serra do Cabral, 12-IX-2003, E.D. Silva et al. 187 (UEC); idem, 28-VII-1976, P. Gibbs et al. 2-376 (UEC); idem, 15-IV-1996, 

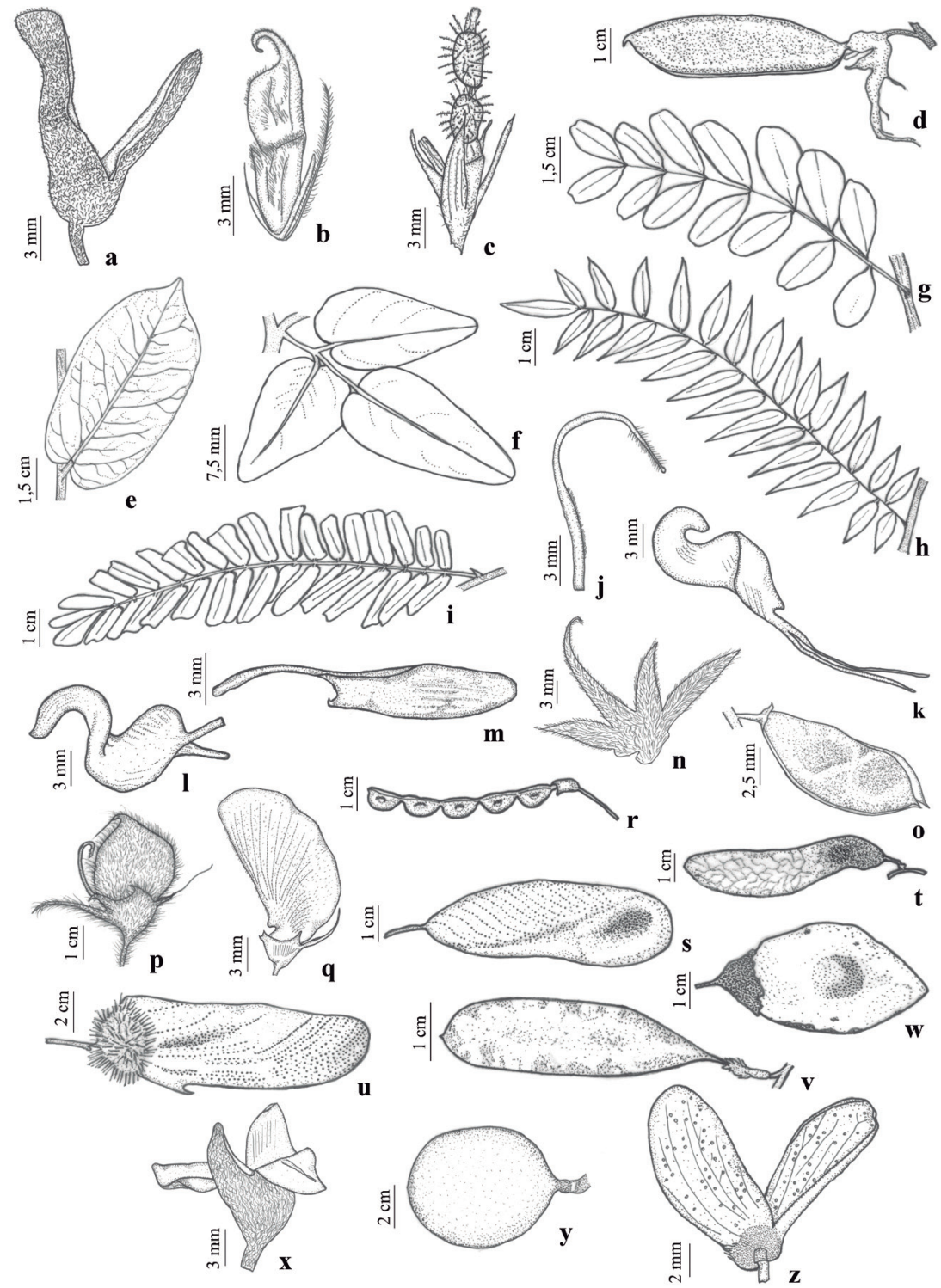

Figura 2. a. Harpalyce brasiliana var. brasiliana (Silva 99). b. Stylosanthes viscosa (Silva 231). c. Zornia subsessilis (Silva 283). d. Crotalaria maypurensis (Silva 114). e. Camptosema coccineum var coccienum (Silva 183). f. Oryxis monticola (Silva 74). g. Platypodium elegans (Hatschbach 69401). h. Dalbergia acuta (Hatschbach 72247). i. Machaerium hirtum (Hatschbach 61778). j. Oryxis monticola (Silva 74). k. Macroptilium bracteatum (Souza 22416). 1. Vigna peduncularis (Silva 185). m. Camptosema coriaceum (Silva 177). n. Galactia graewifolia (Silva 228). o. Rhynchosia edulis (s.c. RB160242). p. Eriosema strictum var. crinitum (Silva 208 A). q. Centrosema brasilianum var. brasilianum (Silva 59). r. Aeschynomene marginata var. marginata (Silva 108). s. Platypodium elegans (Hatschbach 40760). t. Machaerium hirtum (Noronha 539). u. Centrolobium tomentosum (Bentoncini UEC118139). v. Dalbergia miscolobium (Silva 278). w. Pterodon pubescens (Mendonça 3402). x. Centrolobium tomentosum (Bentoncini 1057). y. Andira humilis (Hastchbach UEC7498). z. Pterodon pubecens (Hatschbach 67221).

Figure 2. a. Harpalyce brasiliana var. brasiliana (Silva 99). b. Stylosanthes viscosa (Silva 231). c. Zornia subsessilis (Silva 283). d. Crotalaria maypurensis (Silva 114). e. Camptosema coccineum var coccienum (Silva 183). f. Oryxis monticola (Silva 74). g. Platypodium elegans (Hatschbach 69401). h. Dalbergia acuta (Hatschbach 72247). i. Machaerium hirtum (Hatschbach 61778). j. Oryxis monticola (Silva 74). k. Macroptilium bracteatum (Souza 22416). 1.Vigna peduncularis (Silva 185). m. Camptosema coriaceum (Silva 177). n. Galactia graewifolia (Silva 228). o. Rhynchosia edulis (s.c. RB160242). p. Eriosema strictum var. crinitum (Silva 208 A). q. Centrosema brasilianum var. brasilianum (Silva 59). r. Aeschynomene marginata var. marginata (Silva 108). s. Platypodium elegans (Hatschbach 40760). t. Machaerium hirtum (Noronha 539). u. Centrolobium tomentosum (Bentoncini UEC118139). v. Dalbergia miscolobium (Silva 278). w. Pterodon pubescens (Mendonça 3402). x. Centrolobium tomentosum (Bentoncini 1057). y. Andira humilis (Hastchbach UEC7498). z. Pterodon pubecens (Hatschbach 67221). 
G. Hatschbach et al. 64812 (MBM); idem, 13-V-1977, P.E. Gibbs et al. 5055 (UEC); Várzea de Palma, 27-IV-1963, A.P. Duarte 7793 (UEC); Buenópolis, Serra do Cabral, 12-X-1988, R.M. Harley 24863 (SP).

6. Centrolobium Mart. ex Benth., Comm. Leg. Gen.: 31 (1837).

Árvores. Folhas imparipinadas, multifolioladas. Folíolos glandulosos, glândulas alaranjadas, peltadas ou sésseis. Flores amarelas. Cálice 4-laciniado. Androceu monadelfo. Anteras uniformes. Ovário giboso, glanduloso, 3-ovulado. Sâmara calcarada, com núcleo seminífero basal fortemente diferenciado da ala, longo-equinado.

Gênero exclusivamente neotropical pertencente à tribo Dalbergieae Bronn ex DC. com sete espécies distribuídas em florestas desde o norte da América do Sul até a região Sul do Brasil (Lima 1985, Lewis et al. 2005)

6.1. Centrolobium tomentosum Guill. ex Benth., J. Bot. 2: 66. 1840.

Material selecionado: BRASIL. MinAs GeRAIS: Várzea de Palma, Serra do Cabral, 16-I-1996, G. Hatschbach et al. 64144 (BHCB).

7. Centrosema (DC.) Benth., Comm. Legum. Gen.: 53. 1837.

Ervas ou subarbustos, volúveis ou prostrados. Folhas 3-5-7-folioladas, raro 3-5-digitadas ou unifolioladas com pecíolo alado. Flores violáceas, róseas, azuladas ou alvas. Cálice 5-dentado a 5-laciniado. Vexilo giboso na base, a maioria calcarado no dorso. Androceu diadelfo. Anteras uniformes. Legume linear, reto ou falcado.

Gênero pertencente à tribo Phaseoleae Bronn ex DC. com 36 espécies distribuídas pela região neotropical, com a maioria delas encontradas no Brasil (Barbosa-Fevereiro 1977, Miotto 1987, Lewis et al. 2005). No Brasil ocorrem 26 espécies (Barbosa-Fevereiro 1977).

Chave para as espécies de Centrosema da Serra do Cabral

1. Folhas pinadas, 3-folioladas; folíolos $1,5-2,5 \mathrm{~cm}$ larg.

2. Fruto liso entre as nervuras C. brasilianum var. brasilianum

2. Fruto estriado entre as nervuras ... C. angustifolium

1. Folhas digitadas, 3-folioladas; folíolos até $0,6 \mathrm{~cm}$ larg. C. venosum
7.1. Centrosema angustifolium (Kunth) Benth., Comm. Legum. Gen.: 54. 1837.

Material selecionado: BRASIL. Minas Gerais: Joaquim Felício, Serra do Cabral, 4-V-2003, E.D. Silva et al. 90 (UEC).

7.2. Centrosema brasilianum (L.) Benth. var. brasilianum, Comm. Legum. Gen.: 54. 1837.

Material selecionado: BRASIL. Minas Gerais: Joaquim Felício, Serra do Cabral, 2-V-2003, E.D. Silva et al. 59 (UEC); idem, 30-VII-1976, P. Gibbs et al. 2464 (UEC); idem, 13-V-1977, P.E. Gibbs 5076 (UEC); Buenópolis, Serra do Cabral, 16-V-1977, P.E. Gibbs et al. 5161 (SPF).

7.3. Centrosema venosum Mart. ex Benth., Fl. bras. 15(1): 133. 1862.

Material selecionado: BRASIL. Minas Gerais: Joaquim Felício, Serra do Cabral, 2-V-2003, E.D. Silva et al. 59 (UEC); idem, 7-XII-2003, E.D. Silva et al. 203 (UEC); idem, 17-XI-1997, G. Hatschbach et al. 67189 (MBM).

8. Clitoria L., Sp. P1. 2: 753. 1753.

Ervas, subarbustos ou arbustos, volúveis a escandentes, suberetos a prostrados, ou árvores. Folhas pinadas, trifolioladas a plurifolioladas. Inflorescência axilar, 1-2-flora. Bractéolas geralmente maiores que as brácteas. Flores róseas, brancas ou violáceas. Cálice tubuloso, 5-dentado. Androceu monadelfo a diadelfo. Estilete com ápice levemente dilatado, longitudinalmente barbado. Legume linear.

Gênero pantropical pertencente à tribo Phaseoleae Bronn ex DC. com aproximadamente 62 espécies (Lewis et al. 2005).

Chave para as espécies de Clitoria da Serra do Cabral

1. Subarbusto virgado; folíolos 7-17 cm compr., longo-oblongos a lineares; pecíolo menor que $1 \mathrm{~cm}$ compr.; flores lilases, ca. 7,5 cm compr. C. guianensis

1. Subarbusto escandente; folíolos $5 \mathrm{~cm}$ compr., elípticos a lanceolados; pecíolo maior que $1 \mathrm{~cm}$ compr.; flores brancas, ca. $4 \mathrm{~cm}$ compr. C. falcata

8.1. Clitoria falcata Lam., Encycl. Méth. Bot. 2(1): 51. 1786.

Material selecionado: BRASIL. Minas Gerais: Joaquim Felício, Serra do Cabral, 2-V-2003, E.D. Silva 
et al. 59 (UEC); idem, 7-XII-2003, E.D. Silva et al. 214 (UEC).

8.2. Clitoria guianensis (Aubl.) Benth., J. Proc. Soc. Bot. 2: 40. 1858.

Material selecionado: BRASIL. Minas Gerais: Joaquim Felício, Serra do Cabral, 7-XII-2003, E.D. Silva et al. 202 (UEC); Várzea de Palma, Serra do Cabral, 7-X-1992, E.M. Teixeira et al. (BHCB3130).

9. Collaea DC., Ann. Sci. Nat. 4: 96. 1825.

Ervas a arbustos. Folhas sésseis a subsésseis, 3-folioladas. Raque da inflorescência nodosa. Flores geralmente vermelhas. Cálice 4-laciniado, lacínias maiores que o tubo, internamente glabro. Vexilo sem calos, às vezes giboso. Filamento vexilar concrescido com os demais até a metade. Ovário subséssil, pluriovulado. Legume séssil, linear, coriáceo.

Gênero exclusivamente sul americano pertencente à tribo Phaseoleae Bronn ex DC., formado por sete espécies (Lewis et al. 2005).

9.1 Collaea speciosa (Loisel.) DC., Mem. Leg. 6: 245. 1825.

Material selecionado: BRASIL. Minas Gerais: Francisco Dumont, Serra do Cabral, 16-V-2001, G. Hatschbach et al. 72108 (MBM).

10. Crotalaria L., Sp. Pl. 2: 714. 1753.

Ervas a arbustos. Folhas simples, unifolioladas ou digitado-trifolioladas, sésseis ou pecioladas. Flores amarelas. Cálice bilabiado ou com lacínios subiguais. Vexilo 2-apendiculado na base. Carena com ápice desenvolvido, torcido ou não. Androceu monadelfo. Anteras dimorfas, alternando 5 longas basifixas e 5 menores dorsifixas. Ovário 2-pluriovulado. Legume inflado. Sementes reniformes.

Crotalaria é o único representante nativo da tribo Crotalarieae (Benth.) Hutch. na América do Sul (Flores 2004). Possui aproximadamente 690 espécies encontradas nos trópicos e subtrópicos com o maior número de espécies ocorrendo na África (Polhill 1994, Lewis et al. 2005).

Nos neotrópicos ocorrem ca. 70 espécies, sendo o Brasil o país da América do Sul com o maior número de espécies (Flores \& Miotto 2001), 31 nativas e 11 exóticas (Flores 2004).
Chave para as espécies de Crotalaria da Serra do Cabral

1. Folhas simples

2. Estípulas ausentes; fruto velutino C.juncea

2. Estípulas presentes; fruto glabro

3. Inflorescência 1-3-flora; brácteas 1-2 mm larg., elíptico-lanceoladas a linear-setáceas C. velutina

3. Inflorescência 6-20-flora; brácteas 3-9 mm larg., ovado-lanceoladas a foliáceas

4. Ramos denso-hirsutos; tricomas longos, patentes C. flavicoma

4. Ramos velutinos ou seríceos; tricomas curtos, adpressos

5. Carena com ápice curto, encurvado ..... C. martiana subsp. martiana

5. Carena com ápice longo, reto C. martiana subsp. mohlenbrockii

1. Folhas digitado-3-folioladas

6. Subarbusto $50-80 \mathrm{~cm}$ alt.; inflorescência 2-5-flora; brácteas ca. $4 \mathrm{~mm}$ compr.... C. maypurensis

6. Arbusto 1,5-2 m alt.; inflorescência

7-29-flora; brácteas 7-9 mm compr. ..... C. micans

10.1. Crotalaria flavicoma Benth., Ann. Nat. Hist. 3: 429. 1839.

Material selecionado: BRASIL. Minas Gerais: Joaquim Felício, Serra do Cabral, 2-V-2003, E.D. Silva et al. 54 (UEC); idem, 13-III-1999, V.C. Souza et al. 22104 (ESA); idem, 13-V-1977, P.E. Gibbs et al. 5029 (UEC, MBM); idem, 22-XI-1984, M.C.H. Mamede et al. 6338 (MBM); idem, 14-X-2001, G. Hatschbach et al. 71997 (MBM, BHCB); idem, 17-I-1996, G. Hatschbach et al. 64230 (MBM); idem, 8-VII-2001, P. Fiaschi 870 (BHCB); idem, 5-VII-1985, R. Kral 72579 (SP); Várzea de Palma, Serra do Cabral, 13-III-1999, G. Hatschbach et al. 69001 (MBM); idem, 17-VI-1990, D.C. Zappi et al. 61196 (BHCB).

10.2. Crotalaria juncea L., Sp. P1. 2: 714. 1753.

Material selecionado: BRASIL. Minas Gerais: Joaquim Felício, Serra do Cabral, 7-XII-2003, E.D. Silva et al. 232 (UEC).

10.3. Crotalaria martiana Benth. subsp. martiana, Hook. London J. Bot. 2: 482. 1843.

Material selecionado: BRASIL. Minas Gerais: Joaquim Felício, Serra do Cabral, 9-IX-2003, E.D. Silva et al. 126 (UEC). 
10.4. Crotalaria martiana subsp. mohlenbrockii (Windler \& Skinner) Planchuelo, Candollea 53(2): 465. 1998.

Material selecionado: BRASIL. Minas Gerais: Augusto de Lima, 9-IX-2003, E.D. Silva et al. 124 (UEC).

10.5. Crotalaria maypurensis Kunth, Nov. Gen. Sp. P1. 6: 403. 1824.

Material selecionado: BRASIL. Minas Gerais: Joaquim Felício, Serra do Cabral, 5-V-2003, E.D. Silva et al. 115 (UEC); idem, 19-III-1994, C.M. Sakuragui et al. s.n. (BHCB83891); idem, 14-IV-1996, G. Hatschbach et al. 64671 (MBM); idem, 13-II-1988, W.W. Thomas (SPF63622); idem, 19-III-1994, C.M. Sakuragui et al. s.n. (SPF97398).

10.6. Crotalaria micans Link, Enum. Pl. Hort. Berol. 2: 228.1822.

Material selecionado: BRASIL. Minas Gerais: Joaquim Felício, Serra do Cabral, 2-V-2003, E.D. Silva et al. 58 (UEC); Buenópolis, Serra do Cabral, 15-V-1977, P.E. Gibbs et al. 5166 (UEC); idem, 15-V-1977, P.E. Gibbs et al. 5160 (MBM).

10.7. Crotalaria velutina Benth., Ann. Nat. Hist. 3 : 429. 1839.

Material selecionado: BRASIL. Minas Gerais: Buenópolis, Serra do Cabral, 9-IX-2003, E.D. Silva et al. 139 (UEC).

\section{Dalbergia L. f., Suppl. P1. 52: 316. 1782.}

Árvores, arbustos escandentes ou lianas. Folhas imparipinadas, raro unifolioladas. Folíolos alternos. Flores pequenas e numerosas, brancas, cremes, amarelas, púrpuras ou violetas. Carena frequentemente muito menor que as asas. Estames 10 ou 9, monadelfos ou diadelfos. Anteras com deiscência apical, raro por aberturas longitudinais. Ovário longo-estipitado. Legume samaróide, estipitado, nervuras marginais inconspícuas.

Gênero pantropical pertencente à tribo Dalbergieae Bronn ex DC. com aproximadamente 250 espécies (Carvalho 1997, Lewis et al. 2005). No Brasil ocorrem 39 espécies (Carvalho 1997).

Chave para as espécies de Dalbergia da Serra do Cabral

1. Pecíolo 0,2-0,3 cm compr.; folíolos ovadolanceolados, 0,2-0,6 cm larg., ápice agudo; cálice e corola tomentosos; ovário tomentoso D. acuta
1. Pecíolo 1,2-2 cm compr.; folíolos ovadooblongos, 0,7-1,1 cm larg.; ápice emarginado a arredondado; cálice e corola glabros; ovário com tricomas glandulares .... D. miscolobium

11.1. Dalbergia acuta Benth., J. Linn. Soc., Bot. 4: 36. 1860 .

Material selecionado: BRASIL. Minas Gerais: Várzea de Palma, Serra do Cabral, 20-V-2001, G. Hatschbach et al. 72247 (MBM).

11.2. Dalbergia miscolobium Benth., J. Linn. Soc. Bot. 4: 35. 1860.

Material selecionado: BRASIL. Minas Gerais: Joaquim Felício, Serra do Cabral, 7-VII-2004, E.D. Silva 278 (UEC); idem, 10-VII-2001, V.C. Souza et al. 25581 (ESA, BHCB).

12. Desmodium Desv., J. Bot. Agric. 1: 122, pl. 5, f. 15. 1813.

Ervas prostradas a decumbentes, subarbustos ou arbustos. Folhas 1-3(-5)-folioladas. Inflorescência em racemo, panícula ou fascículo. Flores róseas a lilases. Androceu diadelfo, $9+1$ estames. Ovário séssil a estipitado, pluriovulado. Fruto lomento, 1-9-articulado, indeiscente a deiscente, com istmo central ou marginal.

Gênero pantropical pertencente à tribo Desmodieae (Benth.) Hutch. com aproximadamente 275 espécies (Azevedo 1981, Lewis et al. 2005).

12.1. Desmodium incanum DC., Prodr. 2: 332. 1825.

Material selecionado: BRASIL. Minas Gerais: Joaquim Felício, Serra do Cabral, 7-XII-2003, E.D. Silva 204 (UEC).

\section{Dioclea Kunth, Nov. Gen. 6: 437. 1823.}

Lianas. Folhas pinadas ou trifolioladas. Folíolos elípticos a obovados. Inflorescência nodosa. Pedúnculo ereto, com estípulas e nós. Flores reflexas. Vexilo plicado, biauriculado, bicaloso, glabro. Androceu monadelfo ou dialdelfo, estames férteis com anteras uniformes alternando com estaminódios. Legumes lineares, oblongos ou semi-orbiculares, plano-compressos ou túrgidos.

Gênero pertencente à tribo Phaseoleae Bronn ex DC. com 40 espécies encontradas na América do Sul, América Central e Ásia (Lewis et al. 2005). 
13.1. Dioclea latifolia Benth., Comm. Legum. Gen.: 69. 1837.

Material selecionado: BRASIL. Minas Gerais: Joaquim Felício, Serra do Cabral, 3-V-2003, E.D. Silva et al. 71 (UEC).

14. Eriosema (DC.) G. Don, Gen. Hist. 2: 347. 1832.

Ervas ou arbustos, eretos ou prostrados. Folhas unifolioladas ou trifolioladas, com folíolos muito diversos em tamanho e forma. Flores amarelas, com estrias violeta ou vermelho-púrpuras. Vexilo obovado a oblongo com base auriculada. Estames diadelfos. Anteras uniformes. Ovário séssil a subséssil, biovulado. Fruto 2-valvado, amplamente oblongo a orbicular, rombóide, com rostro fortemente encurvado. Sementes 2.

Gênero pantropical pertencente à tribo Phaseoleae Bronn ex DC. com aproximadamente 150 espécies, sendo a maioria delas encontrada na África (Grear 1970, Lewis et al. 2005). Apesar de pantropical, ocorre em três áreas bastante delimitadas: América, África (incluindo Madagascar), Sudeste da Ásia e Norte da Austrália. Todas as espécies de Eriosema são tipicamente de savanas (Grear 1970).

Chave para as espécies de Eriosema da Serra do Cabral

1. Ramos e demais partes vegetativas clarotomentosas; folíolos elípticos, obovados ou largo-lanceolados, 2-3,5 cm larg. ..... E. floribundum

1. Ramos e demais partes vegetativas pubérulas a canescente-seríceas ou longo-pilosas; folíolos linear-oblongos ou estreito-lanceolados, $0,5-1,5 \mathrm{~cm}$ larg.

2. Folíolos pubérulos a canescente-seríceos, tricomas adpressos a subpatentes; flores ca. 1,7 cm compr., amarelas com estrias vináceas E. strictum

2. Folíolos longo-pilosos, tricomas patentes, amarelados; flores ca. 1,4 cm compr., amarelas, sem estrias .... E. crinitum var. crinitum

14.1. Eriosema crinitum (Kunth) G. Don var. crinitum, Gen. Hist. 2: 348. 1832.

Material selecionado: BRASIL. Minas Gerais: Joaquim Felício, Serra do Cabral, 7-XII-2003, E.D. Silva et al. $208 \mathrm{~A}$ (UEC).
14.2. Eriosema floribundum Benth., Linnaea 22 524. 1849.

Material selecionado: BRASIL. Minas Gerais: Joaquim Felício, Serra do Cabral, 12-IX-2003, E.D. Silva et al. 171 (UEC); idem, 22-XI-1984, B. Stannard et al. 6323 (MBM); idem, 2-IX-1985, R.M. Silva \& T.B. Cavalcante CFCR 8246 (SPF).

14.3. Eriosema strictum Benth., Linnaea 22: 520. 1849.

Material selecionado: BRASIL. Minas Gerais: Joaquim Felício, Serra do Cabral, 4-V-2003, E.D. Silva et al. 91 (UEC).

15. Galactia P. Browne, Civ. Nat. Hist. Jamaic.: 298. 1756.

Ervas a arbustos, eretos, virgados ou escandentes. Folhas unifolioladas, trifolioladas ou pinadas. Inflorescência nodosa. Flores violáceas a rosadas. Cálice 4-laciniado, lacínios maiores que o tubo. Estames diadelfos ou pseudomonadelfos. Filamento vexilar concrescido com os demais apenas na base. Anteras uniformes. Ovário subséssil. Estilete glabro. Legume linear, reto a subfalcado, plano-compresso a raramente túrgido.

Gênero pantropical pertencente à tribo Phaseoleae Bronn ex DC. com 55-60 espécies, sendo a maioria encontrada nas América do Sul e Central (Burkart 1971, Lewis et al. 2005).

\section{Chave para as espécies de Galactia da} Serra do Cabral

1. Folhas unifolioladas, subsésseis; pecíolo 2-3 mm compr.; folíolos membranáceos; vexilo lanceolado, seríceo .............. G. grewiaefolia

1. Folhas 3-folioladas, pecioladas; pecíolo 1,1-1,9 cm compr.; folíolos subcoriáceos; vexilo orbicular, glabro ..................... G. crassifolia

15.1. Galactia crassifolia (Benth.) Taub., Nat. Pflanzenfam. 3(3): 368. 1894.

Material selecionado: BRASIL. Minas Gerais: Joaquim Felício, Serra do Cabral, 9-IX-2003, E.D. Silva et al. 147 (UEC); idem, 13-III-1999, V.C. Souza \& J.P. Souza 22136 (ESA); idem, 6-XI-1987, J.R. Pirani et al. CFCR 11627 (SPF).

15.2. Galactia grewiaefolia Taub., Nat. Pflanzenfam. 3(3): 368. 1894.

Material selecionado: BRASIL. Minas Gerais: Joaquim Felício, Serra do Cabral, 9-XII-2003, 
E.D. Silva et al. 228 (UEC); idem, 17-XI-1997, G. Hatschbach \& G. Barbosa 67172 (MBM).

16. Harpalyce Moç. \& Sessé ex DC., Prodr. 2: 523. 1825.

Subarbustos a pequenas árvores. Folhas imparipinadas com mais de quatro folíolos. Folíolos com face abaxial glandulosa. Flores laranjaavermelhadas, branco-rosadas a roxo-escuras, brancas a branco-esverdeadas. Cálice bilabiado; os dois lobos superiores e os 3 lobos inferiores unidos totalmente em 2 lobos inteiros, lobo superior cuculado. Androceu monadelfo. Anteras dimorfas. Ovário pluriovulado. Legume séssil, 2-valvado, oblongo a ovado-oblongo. Gênero pertencente à tribo Brongniartieae (Benth.) Hutch. com 24 espécies distribuídas pela América Central e do Sul (Arroyo 1976, Lewis et al. 2005). No Brasil ocorrem sete espécies que se desenvolvem principalmente em áreas de Cerrado, com uma espécie (Harpalyce brasiliana Benth.) que se estende até a Caatinga. Segundo Arroyo (1976), 80\% dos táxons descritos de Harpalyce são endêmicos, restritos normalmente a um único tipo de solo.

16.1. Harpalyce brasiliana Benth. var. brasiliana, J. Bot. 3: 210. 1841.

Material selecionado: BRASIL. Minas Gerais: Joaquim Felício, Serra do Cabral, 4-V-2003, E.D. Silva et al. 97 (UEC); idem, 15-IV-1996, G. Hatschbach et al. 64820 (MBM); idem, 15-IV-1996, G. Hatschbach et al. 64820 (BHCB); Francisco Dumont, Serra do Cabral, 22-III-1994, C.M. Sakuragi et al. CFCR 15342 (SPF).

17. Indigofera L., Sp. P1., 2: 751. 1753.

Arbustos eretos. Folhas alternas, imparipinadas. Folíolos opostos a alternos com tricomas malpiguiáceos. Flores em racemos axilares, densos. Carena 2-apendiculada. Estames diadelfos $9+1$. Filetes alternadamente longos e curtos. Anteras elípticas com conectivo apiculado. Ovário subséssil. Legume cilíndrico, reto a encurvado. Sementes quadrangulares.

Gênero pantropical pertencente à tribo Indigofereae Benth. com 700 espécies (Lewis et al. 2005). No Brasil ocorrem apenas 11 espécies (Moreira \& Tozzi 1997).

17.1. Indigofera lespedezioides Kunth, Nov. Gen. Sp. 6: 457. 1824.

Material selecionado: BRASIL. Minas GeraIS: Serra do Cabral, 5-III-1970, Irwin et al. s.n. (RB 158684).
18. Leptolobium Vogel, Linnaea 11: 388.

Subarbustos a árvores. Folhas imparipinadas, raro paripinadas. Folíolos 3-21. Pétalas 5, livres, semelhantes entre si, sem diferenciação de vexilo, brancas, não auriculadas. Estames 10, uniformes, livres. Fruto samaróide, raro nucóide.

Gênero neotropical pertencente à tribo Sophoreae Spreng. ex DC. com 11 espécies distribuídas do sul do México até o norte da Argentina. Todas as espécies ocorrem no Brasil, sendo seis endêmicas (Rodrigues \& Tozzi 2008).

Chave para espécies de Leptolobium da Serra do Cabral

1. Folíolos 3-5, ovados, obovados ou elípticos, nunca oblongos, mais de 5,5 cm compr., face abaxial denso-pubescente; eixo da inflorescência maior que $5 \mathrm{~cm}$ compr. ..................... L. dasycarpum

1. Folíolos 7-9, oblongo-elípticos, raro ovados, até $3 \mathrm{~cm}$ compr., face abaxial glabra; eixo da inflorescência menor que $5 \mathrm{~cm}$ compr. L. brachystachyum

18.1 Leptolobium brachystachyum (Benth.) Sch. Rodr. \& A.M.G. Azevedo, Taxon 57: 980. 2008.

Material selecionado: BRASIL. Minas Gerais: Joaquim Felício, Serra do Cabral, 17-XI-1997, G. Hatschbach et al. 67167 (BHCB, SP); idem, 16-V-1999, V.C. Souza et al. 22428 (BHCB).

18.2. Leptolobium dasycarpum Vogel, Linnaea 11: 388. 1837.

Material selecionado: BRASIL. Minas Gerais: Joaquim Felício, Serra do Cabral, 16-V-1999, G. Hatschbach et al. 67174 (MBM, SP); idem, 16-X-1997, G. Hatschbach et al. 67174 (MBM); idem, 16-V-1999, V.C. Souza et al. 22439 (BHCB); Várzea de Palma, Serra do Cabral, 12-III-1998, G. Hatschbach et al. 61771 (MBM, BHCB).

19. Lonchocarpus Kunth, Nov. Gen. Sp. 6: 300. 1824.

Arbustos ou árvores. Folhas alternas, imparipinadas, 4-14(-20)-folioladas, raro uni ou trifolioladas. Estípulas rudimentares. Folíolos opostos, raro subopostos. Carena igual ou maior que as asas. Androceu monadelfo, raro sub-diadelfo, estames 10. Anteras uniformes. Ovário séssil a curto-estipitado. Legume samaróide com região seminífera mediana, nervuras marginais proeminentes. 
Gênero pertencente à tribo Millettieae Miq. com 120 espécies distribuídas pela América do Sul, Central e África (Tozzi 1989, Neubert \& Miotto 1996, Lewis et al. 2005).

19.1. Lonchocarpus costatus Benth., J. Linn. Soc. Bot. 4 (suppl.): 100. 1860.

Material selecionado: BRASIL. Minas Gerais: Várzea de Palma, Serra do Cabral, 13-III-1999, G. Hatschbach et al. 69037 (MBM).

20. Lupinus L., Sp. P1. 2: 721. 1753.

Ervas ou subarbustos. Folhas 3-11-folioladas, unifolioladas ou unifolioladas e digitadas no mesmo indivíduo. Flores vermelhas, vináceas, roxas, violetas, lilases, azuis ou róseas, raramente brancas. Vexilo não apendiculado. Estames monadelfos, cinco com filetes curtos e anteras longas basifixas, cinco com filetes longos e anteras curtas e dorsifixas. Legume subcompresso.

Gênero pertencente à tribo Genisteae (Adans.) Benth. com 220-230 espécies subarbustivas, encontradas nas Américas, na região do Mediterrâneo estendendo-se até a região montanhosa da África tropical (Monteiro \& Gibbs 1986, Polhill 1994, Lewis et al. 2005).

20.1. Lupinus parvifolius Gardner, Hooker's Icon. P1. 6(1): 521. 1843.

Material selecionado: BRASIL. Minas GeraIs: Várzea de Palma, 25-V-1982, H.P. Batista 643 (MBM).

21. Machaerium Pers., Syn. P1. 2(2): 276. 1807.

Árvores ou arbustos escandentes. Folhas imparipinadas. Flores brancas, creme-esverdeadas, lilases ou vináceas. Estames 10, monadelfos, às vezes diadelfos com o vexilar livre ou distribuídos em dois feixes de $5+5$. Ovário estipitado, uniovulado, disco presente na base do ovário. Sâmara com núcleo seminífero basal, pouco diferenciado.

Gênero pertencente à tribo Dalbergieae Bronn ex DC. com 130 espécies distribuídas do México até a Argentina, com representantes ocorrendo na costa oeste africana (Hoehne 1941, Sartori \& Tozzi 1999, Lewis et al. 2005).

Chave para as espécies de Machaerium da Serra do Cabral

1. Ramos aculeados; folhas 33-35-folioladas; folíolos oblongos, até $3 \mathrm{~mm}$ larg.; flores lilases ..... M. hirtum
1. Ramos inermes, folhas 9-folioladas; folíolos elípticos a obovados, até $1,5 \mathrm{~cm}$ larg.; flores brancas M. stipitatum

21.1. Machaerium hirtum (Vell.) Stellfeld, Tribuna Farm. 12: 132. 1944.

Material selecionado: BRASIL. Minas Gerais: Várzea de Palma, Serra do Cabral, 12-III-1995, G. Hatschbach et al. 61778 (MBM, BHCB).

21.2. Machaerium stipitatum (DC.) Vogel, Linnaea 11: 189. 1837.

Material selecionado: BRASIL. MinAs GERAIS: Várzea de Palma, 15-I-1996, G. Hatschbach et al. 64088 (MBM, BHCB, SP).

22. Macroptilium (Benth.) Urb., Symb. Antill. 9(4): 457. 1928.

Ervas ou subarbustos, eretos, prostrados ou volúveis. Estípulas sem expansões. Folíolos 1-3, lobados ou não. Pseudoracemos axilares, 2 flores cada, nodosidades inconspícuas. Vexilo glabro, base 2-apendiculada. Carena torcida para o lado. Androceu com estame vexilar geniculado. Estigma piloso. Estilete barbado, dilatado no ápice. Legumes retos ou curvos. Sementes 2-22.

Gênero pertencente à tribo Phaseoleae Bronn ex DC. com 17 espécies nativas das Américas, sendo duas delas introduzidas na África (Lewis et al. 2005). No Brasil são encontradas 10 espécies (Fevereiro 1987, Moreira 1997).

22.1. Macroptilium bracteatum (Nees \& Mart.) Maréchal \& Baudet, Bull. Jard. Bot. Nation. Belg. 44: 443. 1974.

Material selecionado: BRASIL. Minas Gerais: Augusto de Lima, Serra do Cabral, 15-V-1999, V.C. Souza et al. 22416 (ESA, MBM ,UEC).

23. Myroxylon L.f., Supp. Plant. 34: 233. 1781.

Árvores. Ramos lenticelados. Folhas imparipinadas, até 15 -folioladas. Raque foliar sulcada. Folíolos com pontos e linhas translúcidas. Flores brancas. Cálice campanulado, com lacínios obsoletos ou 5-laciniado. Vexilo com mácula esverdeada. Androceu com 10 estames livres entre si. Anteras apiculadas, sagitadas. Ovário uniovulado. Sâmara com ala basal e região seminífera apical. Semente 1.

Gênero pertencente à tribo Sophoreae Spreng ex DC. com apenas duas espécies, distribuídas pelas 
Américas Central e do Sul (Lewis et al. 2005). No Brasil ocorrem as duas espécies (Sartori 2000).

23.1. Myroxylon peruiferum L. f., Suppl. Plant. 34: 233. 1781.

Material selecionado: BRASIL. Minas Gerais: Buenópolis, Serra do Cabral, 16-VIII-2002, G. Hatschbach et al. 73465 (BHCB, SPF).

24. Oryxis A. Delgado \& G.P. Lewis, Kew Bull. 52(1): 221. 1997.

Ervas ou subarbustos, suberetos, prostrados a volúveis. Estípulas não expandidas além do ponto de inserção. Folíolos 3, não lobados. Pseudoracemos com 3(-7) flores cada, nodosos. Flores violáceas, escarlates a amarelas. Vexilo com 2 apêndices basais. Carena encurvada, frequentemente rostrata. Androceu diadelfo com estame vexilar basalmente giboso. Estilete barbado, não dilatado no ápice. Legume falcado a linear. Sementes 8-9.

Gênero pertencente à tribo Phaseoleae Bronn ex DC. com uma única espécie endêmica do Brasil (Lewis et al. 2005).

24.1. Oryxis monticola (Mart. ex Benth.) A. Delgado \& G.P. Lewis, Kew Bull. 52(1): 221. 1997.

Material selecionado: BRASIL. Minas Gerais: Joaquim Feílicio, Serra do Cabral, 5-V-2003, E.D. Silva et al. 74 (UEC); idem, 31-VIII-1985, D.C. Zappi et al. 8081 (MBM); Várzea de Palma, Serra do Cabral, 17-VI-1990, J.R. Pirani et al. CFCR 13214 (SPF).

25. Periandra Mart. ex Benth., Comm. Legum. Gen.: 56. 1837.

Ervas, subarbustos, arbustos ou trepadeiras volúveis. Folhas 3-folioladas, ocasionalmente 1-foliolada na base dos ramos. Flores azul-violáceas ou vermelhas. Vexilo suborbicular, calo conspícuo na base, ungüículo giboso. Estames 10, o vexilar livre, com alternância de filetes longos e curtos. Ovário pluriovulado. Estilete não barbado. Legume linear, reto ou levemente encurvado. Sementes oblongas, 11-20.

Gênero pertencente à tribo Phaseoleae Bronn $e x$ DC. com seis espécies encontradas no Brasil e Bolívia. No Brasil são encontradas todas elas, especialmente em campos Cerrados (Funch \& Barroso 1997, Lewis et al. 2005).
25.1. Periandra mediterranea (Vell.) Taub., Nat. Pflanzenfam. 3(3): 359. 1894.

Material selecionado: BRASIL. Minas Gerais: Joaquim Felício, Serra do Cabral, 3-V-2003, E.D. Silva et al. 75 (UEC); Serra do Cabral, 17-I-1996, G. Hatschbach et al. 64317 (MBM).

26. Platypodium Vogel, Linnaea 11: 420. 1837.

Árvores. Folhas imparipinadas. Folíolos oblongos. Flores amarelas. Cálice turbinado-campanulado. Vexilo amplo-orbicular. Carena pequena, oblonga a obovada. Androceu diadelfo, $5+4$ estames concrescidos com 1 estame livre. Ovário longo-estipitado, pluriovulado. Fruto sâmara, ala basal. Sementes 1-2.

Gênero pertencente à tribo Dalbergieae Bronn ex DC., formado por 1 ou 2 espécies distribuídas pela Bolívia, Brasil, Guatemala, Panamá, Paraguai e Venezuela. (Polhill 1981, Lewis et al. 2005).

26.1. Platypodium elegans Vogel, Linnaea 11: 422. 1837.

Material selecionado: BRASIL. Minas Gerais: Joaquim Felício, Serra do Cabral, 21-X-1999, G. Hatschbach et al. 69401 (MBM).

27. Poiretia Vent., Mén. Cl. Sci. Math. Phys. Inst. Natl. France 8: 4. 1807.

Ervas a arbustos. Caule glanduloso. Folhas 1-3-4-5-folioladas. Folíolos lineares, obovados, ovados, orbiculares, glandulosos, glabros. Inflorescência em racemo, panícula ou espiciforme. Flores amarelas, pediceladas, unibracteoladas ou sem bractéolas. Cálice lobado, glanduloso. Vexilo e carena glandulosos. Androceu monadelfo, 10 estames concrescidos em tubo. Filetes quase do mesmo tamanho. Anteras dimorfas. Ovário estipitado. Óvulos 3-10. Fruto lomento, glanduloso.

Gênero pertencente à tribo Phaseoleae Bronn ex DC. com 11 espécies ocorrentes na América do Sul e Central (Lewis et al. 2005).

Chave para as espécies de Poiretia da Serra do Cabral

1. Subarbusto escandente; ramos pubescentes; flores ca. 0,6 cm compr.; pedicelo ca. $3 \mathrm{~mm}$ compr.; fruto ca. 2,9 cm compr.; sementes 3

1. Subarbusto a arbusto, ereto a virgado; ramos glabros; flores ca. 1,2 cm compr.; pedicelo 4-9 mm compr.; fruto ca. 4,5 cm compr.; sementes 5-6 P. elegans 
27.1. Poiretia elegans Cl. Müll., Rev. Brasil. Bot. 9(1): 26. 1987.

Material selecionado: BRASIL. Minas Gerais: Joaquim Felício, Serra do Cabral, 3-V-2003, E.D. Silva et al. 62 (UEC). Serra do Cabral, 13-V-1977, P.E. Gibbs et al. 5072 (MBM); idem, 14-X-2001, G. Hatschbach 72001 (MBM, BHCB); Francisco Dumont, Serra do Cabral, 23-III-2002, G. Hatschbach et al. 73761 (MBM).

27.2. Poiretia punctata (Willd.) Desv., J. Bot. Agric. 1: 22.1813.

Material selecionado: BRASIL. Minas Gerais: Joaquim Felício, Serra do Cabral, 5-V-2003, E.D. Silva et al. 103 (UEC); Várzea de Palma, 27-XI-1962, A.P. Duarte 7484 (UEC); Buenópolis, 18-XI-1992, R.M. Silva et al. 623 (UEC, SPF).

\section{Pterodon Vogel, Linnaea 11: 384. 1837.}

Árvores. Folhas paripinadas. Flores violáceas a róseo-claras ou quase brancas. Cálice com tubo curto, 5-laciniado, 2 lacínias superiores em forma de asas e as demais curto-dentadas, coalescentes, glandulosas. Pétalas curto-unguiculadas. Androceu monadelfo. Óvulo 1. Fruto criptosâmara. Semente 1, raramente fértil.

Gênero pertencente à tribo Dipterygeae composto por três espécies distribuídas pelo Brasil e Bolívia (Pedersoli 1976, Lewis 1987, Lewis et al. 2005).

28.1. Pterodon pubescens (Benth.) Benth., J. Linn. Soc. Bot.: 127. 1860.

Material selecionado: BRASIL. Minas Gerais: Joaquim Felício, Serra do Cabral, 18-XI-1997, G. Hatschbach et al. 67221 (UEC).

29. Rhynchosia Lour., F1. Cochinch. 2: 425. 1790.

Ervas, subarbustos, arbustos ou lianas. Folhas 1 ou 3-folioladas, com diversos tamanhos e formas. Flores geralmente amarelas, frequentemente com listras púrpuras ou vermelho-acastanhadas. Estames 10, diadelfos. Anteras uniformes. Ovário séssil a subséssil, 1-2-ovulado. Legume 2-valvado, compresso, glanduloso. Sementes 2, raro 1, vermelha e castanha ou vermelha e preta.

Gênero pantropical pertencente à tribo Phaseoleae Bronn ex DC. com aproximadamente 230 espécies (Grear 1978, Lewis et al. 2005).
29.1. Rhynchosia edulis Griseb., Abh. Königl. Ges. Wiss. Göttingen 19: 123. 1874.

Material selecionado: BRASIL. MinAs GeraIs: Serra do Cabral, 5-III-1970, Irwin et al. s.n. (RB160242).

30. Sesbania Scop., Intr. Hist. Nat.: 308. 1777.

Arbustos. Folhas alternas, paripinadas. Inflorescência em racemos axilares curtos. Flores amarelas a rosa ou vermelhas. Vexilo bicaloso. Androceu diadelfo, 9 estames coalescentes e o vexilar livre. Ovário séssil ou estipitado. Legume compresso ou com secção tetragonal. Sementes 5-20, cilíndricas a suborbiculares, não reniformes.

Gênero pantropical pertencente à tribo Sesbanieae Hutch. com 60 espécies (Lewis 1989, Lewis et al. 2005)

30.1. Sesbania exasperata Kunth, Nov. Gen. Sp. (quarto ed.) 6: 534. 1823[1824].

Material selecionado: BRASIL. MinAs Gerais: Serra do Cabral, 11-III-1970, Irwin et al. s.n. (RB158710).

31. Stylosanthes Sw., Prodr. 7: 108. 1788.

Ervas a arbustos. Folhas trifolioladas. Estípulas amplexicaules, bidenteadas. Folíolos elípticos a lanceolados, nervação geralmente proeminente em ambas as faces. Inflorescência em espiga. Flores amarelas ou amarelo-alaranjadas, sésseis, subtendidas por brácteas e bractéolas. Androceu monadelfo, 10 estames. Anteras dimorfas. Óvulos 2, raro 3. Fruto lomento com 1 a 2 artículos, em geral apenas com o artículo superior fértil, estilete persistente.

Gênero pertencente à tribo Dalbergieae Bronn ex DC. com aproximadamente 48 espécies encontradas nos trópicos e regiões temperadas do Velho e do Novo Mundo (Ferreira \& Costa 1979, Costa 1982, Lewis et al. 2005, Costa et al. 2008).

Chave para as espécies de Stylosanthes da Serra do Cabral

1. Lomento 2-articulado; artículo superior com estilete persistente superior a $1 \mathrm{~mm}$ compr., uncinado S. scabra

1. Lomento 1-articulado; artículo com estilete persistente inferior a $1 \mathrm{~mm}$ compr., não uncinado 
2. Subarbusto prostrado; caule muito ramificado; ramos com tricomas longopilosos, patentes, glandulares; folhas perenes; artículo com até $3 \mathrm{~mm}$ compr. S. guianensis

2. Subarbusto ereto a subereto; caule pouco ramificado; ramos com tricomas adpressopilosos a vilosos; folhas caducas; artículo maior que $3 \mathrm{~mm}$ compr. S. gracilis

31.1. Stylosanthes gracilis Kunth, Nov. Gen. 6: 507. 1823.

Material selecionado: BRASIL. Minas Gerais: Joaquim Felício, 23-III-2003, fl., E.D. Silva et al. 14 (UEC).

31.2. Stylosanthes guianensis (Aubl.) Sw., Kongl. Vetensk. Acad. Nya. Handl. 10: 301. 1789.

Material selecionado: BRASIL. Minas Gerais: Joaquim Felício, Serra do Cabral, 11-IX-2003, E.D. Silva et al. 153 (UEC); Serra do Cabral, 16-IV-1996, G. Hatschbach et al. 64882 (MBM).

31.3. Stylosanthes scabra Vogel, Linnaea 12: 69. 1838.

Material selecionado: BRASIL. Minas Gerais: Joaquim Felício, Serra do Cabral, 4-V-2003, E.D. Silva et al. 86 (UEC).

32. Swartzia Schreb., Gen. P1. 2: 518. 1791.

Arbustos ou árvores. Folhas 1-folioladas ou imparipinadas. Pecíolo e raque cilíndricos, marginados ou alados. Inflorescência em racemo, panícula ou fascículo. Corola ausente ou com 1 pétala vexilar, esbranquiçada ou amarela. Estames dimorfos, os maiores 2-11, com anteras oblongas, os menores ca. 100, com anteras orbiculares. Frutos cilíndricos, fusiformes ou ovóides. Sementes 1-15, ariladas.

Gênero pertencente à tribo Swartzieae DC. com 180 espécies distribuídas pela América do Sul, América Central e Caribe (Mansano 1997, Mansano \& Tozzi 1999, Lewis et al. 2005).

Chave para as espécies de Swartzia da Serra do Cabral

1. Flor com 1 pétala; bractéolas presentes na base do cálice; sementes reniformes, planocompressas; estames maiores 4 ...... S. macrostachya

1. Flor apétala; bractéolas ausentes na base do cálice; sementes oblongas, globosas; estames maiores 2 S. pilulifera
32.1. Swartzia macrostachya Benth., Fl. bras. 15(2): 24. 1870 .

Material selecionado: BRASIL. Minas Gerais: Várzea de Palma, 25-II-1964, L. Labouriau \& Valio 1229 (UEC).

32.2. Swartzia pilulifera Benth., J. Bot. 2: 90. 1840.

Material selecionado: BRASIL. Minas Gerais: Joaquim Felício, Serra do Cabral, 23-III-2003, E.D. Silva et al. 15 A (UEC).

\section{Vigna Savi, Nov. Giorn. Lett. 8: 113. 1824.}

Ervas a arbustos, eretos, prostrados ou volúveis. Estípulas estendidas além do ponto de inserção. Folíolos 3, lobados ou não. Carena reta, cocleada, espiralada ou torcida para o lado. Androceu dialdelfo com estame vexilar basalmente geniculado ou giboso. Anteras uniformes. Estilete barbado, prolongado ou não além do ponto de inserção do estigma. Legume linear. Sementes 2-16.

Gênero pertencente à tribo Phaseoleae Bronn ex DC. com aproximadamente 104 espécies distribuídas pelas regiões tropicais e subtropicais de todo o mundo, em particular na África (Moreira 1997, Lewis et al. 2005).

Chave para as espécies de Vigna da Serra do Cabral

1. Folíolos amplo-elípticos ou amplo-ovados, coriáceos; vexilo com par de calosidades longitudinais conspícuas como continuação dos apêndices basais V. firmula

1. Folíolos estreito-elípticos a lanceolados, membranáceos; vexilo com par de calosidades longitudinais pouco conspícuas como continuação dos apêndices basais ... V. peduncularis

33.1. Vigna firmula (Mart. ex Benth.) Maréchal, Mascherpa \& Stainier, Taxon 27(2-3): 201. 1978.

Material selecionado: BRASIL. Minas Gerais: Joaquim Felício, Serra do Cabral, 9-IX-2003, E.D. Silva et al. 128 (UEC).

33.2. Vigna peduncularis (Kunth.) Fawc. \& Rendle, Fl. Jamaica 4(2): 68. 1920.

Material selecionado: BRASIL. Minas Gerais: Augusto de Lima, Serra do Cabral, 4-V-2003, E.D. Silva et al. 83 (UEC).

34. Zornia J.F. Gmel., Sist. Nat. 2(2): 1076. 1791.

Ervas a subarbustos eretos, prostradas ou decumbentes. Folhas 2-4-folioladas. Estípulas 2, 
peltadas. Inflorescência em espiga, raro em racemo. Flores bibracteoladas, amarelas, amarelo-alaranjadas ou raramente brancas, sésseis. Bractéolas peltadas, foliáceas. Androceu monadelfo. Filetes de tamanhos diferentes. Anteras dimorfas, 5 arredondadas, sobre filetes curtos, 5 oblongas, sobre filetes longos. Ovário séssil a subséssil. Lomento com 4-9 artículos cerdosos.

Gênero pertencente à tribo Dalbergieae Bronn ex DC., pantropical, com 75 espécies, sendo mais da metade delas sul americanas (Mohlenbrock 1958, Lewis et al. 2005, Perez 2009).

Chave para as espécies de Zornia da Serra do Cabral

1. Folhas 4-folioladas; folíolos lineares a linear-oblongos, raro linear-lanceolados, 0,1-0,5 cm larg.; pecíolo 1-4 mm compr.; brácteas 6-6,5 × 1,5-2 mm; artículos do lomento ca. $4 \mathrm{~mm}$ compr. Z. subsessilis

1. Folhas 2-folioladas; folíolos lanceolados, 0,5-1,4 cm larg.; pecíolo 7-22 mm compr.; brácteas 7-20 × 2-7 mm; artículos do lomento 1,5-2 mm compr.

2. Brácteas $17-20 \times 6-7 \mathrm{~mm}$; folíolos sem glândulas; lomento subglabro, com todos os artículos cobertos pelas brácteas ou com um único artículo exserto Z. vestita

2. Brácteas 7-12 × 2,5-3 mm; folíolos com glândulas em toda superfície; lomento pubéruloa viloso, commais de doisartículos exsertos nas brácteas

3. Brácteas estreito-lanceoladas, até $12 \mathrm{~mm}$ compr .. Z. latifolia

3. Brácteas largo-lanceoladas a ovadas, até $9 \mathrm{~mm}$ compr. Z. curvata

34.1. Zornia curvata Mohlenbr., Webbia 16(1): 62. 1961.

Material selecionado: BRASIL. Minas Gerais: Joaquim Felício, Serra do Cabral, 7-XII-2003, E.D. Silva et al. 193 (UEC).

34.2. Zornia latifolia Sm., Rees. Cycl. 39: 4. 1819.

Material selecionado: BRASIL. Minas Gerais: Joaquim Felício, Serra do Cabral, 7-XII-2003, E.D. Silva et al. 194 (UEC).

34.3. Zornia subsessilis Fortuna-Perez \& A.M.G. Azevedo, Brittonia 60(3): 271. 2008.

Material selecionado: BRASIL. Minas Gerais: Buenópolis, Serra do Cabral, 9-IX-2003, E.D. Silva et al. 136 (UEC).
34.4. Zornia villosa (Malme) Herter, Rev. Sudamer. Bot. 7: 210. 1943.

Material selecionado: BRASIL. Minas Gerais: Joaquim Felício, Serra do Cabral, 14-III-1997, G. Hatschbach 66231 (MBM).

A subfamília Papilionoideae está representada na área de estudo por 12 tribos, 34 gêneros e 62 espécies. Os gêneros que apresentaram maior número de espécies foram Aeschynomene (6), Crotalaria (6), Zornia (4), Centrosema (3) e Eriosema (3). A tribo mais bem representada é Phaseoleae, com 13 gêneros e 21 espécies.

Das 62 espécies encontradas na Serra do Cabral (tabela 1), 25 são endêmicas do Brasil. Seis espécies (Eriosema floribundum, Leptolobium brachystachyum, Lupinus parvifolius, Oryxis monticola, Poiretia elegans e Zornia subsessilis) e uma variedade (Camptosema coccineum var. nitens) são endêmicas do Estado de Minas Gerais, ocorrendo apenas em algumas serras da Cadeia do Espinhaço. Duas espécies (Aeschynomene vogelii e Dalbergia acuta) e uma subespécie (Crotalaria martiana subsp. martiana) estão limitadas à Cadeia do Espinhaço, sendo encontradas em serras dos Estados de Minas Gerais e Bahia (Chapada Diamantina). Do total de espécies encontradas na área de estudo, 17 estão restritas ao Cerrado, contribuindo significativamente para a caracterização desse tipo de vegetação, sendo algumas delas (Crotalaria flavicoma, C. martiana, Leptolobium brachystachyum e Lupinus parvifolius) fortemente associadas aos Campos Rupestres, outras ocorrendo no Cerrado estendendo-se até a caatinga (Aeschynomene vogelii, Camptosema coriaceum, Centrosema venosum, Eriosema floribundum e Galactia crassifolia); e ainda outras ocorrendo no Cerrado e na Mata Atlântica (Lonchocarpus costatus, Machaerium stipitatum, Myroxylon peruiferum e Oxyris monticola).

A distribuição restrita de grande parte das espécies da subfamília Papilionoideae sugere que alguns táxons desenvolvem-se apenas em fitofisionomias específicas sendo, portanto, dependentes da preservação desses ambientes para a sobrevivência. O número de espécies e a diversidade de gêneros e tribos podem indicar que a família Leguminosae desempenha importante papel na composição e estrutura do Cerrado na Serra do Cabral. 
Tabela 1. Lista de espécies de Papilionoideae da Serra do Cabral, MG, Brasil, hábito, distribuição geográfica e domínio fitogeográfico. arb: arbusto; arv: árvore; lia: liana; BR: Brasil; N: Norte; NE: Nordeste; CO: Centro-Oeste; SE: Sudeste; S: Sul; a: Amazônia; ca: Caatinga; ce: Cerrado; cr: Campo Rupestre; ma: Mata Atlântica; p: Pampa; pt: Pantanal.

Table 1. List of species of Papilionoideae from Serra do Cabral, Minas Gerais State, Brazil, habit, geographical distribuition and phytogeografic domain. arb: shrubs; arv: tree; lia: liana; BR: Brazil; N: North; NE: Northeast; CO: Center West; SE: Southeast; S: South; a: Amazon; ca: Caatinga; ce: Cerrado; cr: Campo Rupestre; ma: Atlantic Forest; p: Pampa; pt: Pantanal.

\begin{tabular}{|c|c|c|c|}
\hline Espécie & Hábito & Distribuição geográfica & Domínio fitogeográfico \\
\hline$\overline{\text { Aeschynomene brasiliana }}$ & arb & BR (não endêmica): N, NE, CO, SE & $\mathrm{a}, \mathrm{ca}, \mathrm{ce}, \mathrm{ma}, \mathrm{pt}$ \\
\hline A. evenia & arb & BR (não endêmica): NE, SE, S & $\mathrm{a}, \mathrm{ca}, \mathrm{ce}, \mathrm{ma}, \mathrm{pt}$ \\
\hline A. histrix & arb & BR (não endêmica): todas as regiões & $\mathrm{a}, \mathrm{ca}, \mathrm{ce}$ \\
\hline A. marginata & arb & BR (endêmica): N, NE, SE & $\mathrm{a}, \mathrm{ca}, \mathrm{ce}$ \\
\hline A. paniculata & arb & BR (não endêmica): todas as regiões & $\mathrm{a}, \mathrm{ca}, \mathrm{ce}, \mathrm{ma}, \mathrm{pt}$ \\
\hline A. vogelii & arb & BR (endêmica): NE (BA), SE (MG) & $\mathrm{ca}, \mathrm{ce}(\mathrm{cr})$ \\
\hline Andira humilis & arb & $\mathrm{BR}$ (endêmica): N, NE, CO, SE & $\mathrm{a}, \mathrm{ca}, \mathrm{ce}$ \\
\hline Bowdichia virgilioides & arv & BR (não endêmica): todas as regiões & $\mathrm{a}, \mathrm{ca}, \mathrm{ce}, \mathrm{ma}, \mathrm{pt}$ \\
\hline Calopogonium caeruleum & arb & BR (não endêmica): todas as regiões & $\mathrm{a}, \mathrm{ca}, \mathrm{ce}, \mathrm{ma}$ \\
\hline $\begin{array}{l}\text { Camptosema coccineum var. } \\
\text { coccineum }\end{array}$ & arb & BR (endêmica): CO (GO), SE (MG) & ce \\
\hline C. coccineum var. nitens & arb & BR (endêmica): SE (MG) & ce \\
\hline C. coriaceum & arb & $\mathrm{BR}$ (endêmica): NE, CO, SE & $\mathrm{ca}, \mathrm{ce}, \mathrm{ma}$ \\
\hline Centrolobium tomentosum & arv & $\mathrm{BR}$ (endêmica): NE, CO, SE, S & $\mathrm{ca}, \mathrm{ce}, \mathrm{ma}$ \\
\hline Centrosema angustifolium & arb & BR (não endêmica): todas as regiões & $\mathrm{a}, \mathrm{ca}, \mathrm{ce}, \mathrm{ma}$ \\
\hline C. brasilianum & arb & BR (não endêmica): todas as regiões & $\mathrm{a}, \mathrm{ca}, \mathrm{ce}, \mathrm{ma}, \mathrm{pt}$ \\
\hline C. venosum & arb & BR (não endêmica): N, NE, CO, SE & ca, ce (cr) \\
\hline Clitoria falcata & arb & BR (não endêmica): todas as regiões & $\mathrm{a}, \mathrm{ce}(\mathrm{cr}), \mathrm{ma}$ \\
\hline C. guianensis & arb & BR (não endêmica): todas as regiões & $\mathrm{a}, \mathrm{ca}, \mathrm{ce}, \mathrm{ma}, \mathrm{pt}$ \\
\hline Collaea speciosa & arb & BR (não endêmica): todas as regiões & $\mathrm{ca}, \mathrm{ce}, \mathrm{ma}$ \\
\hline Crotalaria flavicoma & arb & BR (endêmica): NE, CO, SE & ce (cr) \\
\hline C. juncea & arb & BR (não endêmica): todas as regiões & $\mathrm{a}, \mathrm{ce}, \mathrm{ma}, \mathrm{p}, \mathrm{pt}$ \\
\hline C. martiana subsp. martiana & arb & BR (endêmica): NE (BA), SE (MG) & ce (cr) \\
\hline C. martiana subsp. mohlenbrockii & arb & $\mathrm{BR}$ (não endêmica): N, CO, SE & ce \\
\hline C. maypurensis & arb & BR (não endêmica): todas as regiões & $\mathrm{a}, \mathrm{ca}, \mathrm{ce}, \mathrm{ma}, \mathrm{pt}$ \\
\hline C. micans & arb & BR (não endêmica): todas as regiões & $\mathrm{a}, \mathrm{ca}, \mathrm{ce}, \mathrm{ma}, \mathrm{p}$ \\
\hline C. velutina & arb & BR (endêmica): CO, SE & ce \\
\hline Dalbergia acuta & arv & BR (endêmica): NE (BA), SE (MG) & ca,ce \\
\hline D. miscolobium & arv & BR (endêmica): todas as regiões & $\mathrm{a}, \mathrm{ca}, \mathrm{ce}$ \\
\hline Desmodium incanum & arb & BR (não endêmica): todas as regiões & $\mathrm{a}, \mathrm{ca}, \mathrm{ce}, \mathrm{ma}, \mathrm{p}, \mathrm{pt}$ \\
\hline Dioclea latifolia & lia & BR (endêmica): NE, CO, SE & ce \\
\hline Eriosema crinitum & arb & BR (não endêmica): todas as regiões & $\mathrm{ca}, \mathrm{ce}, \mathrm{ma}$ \\
\hline E. floribundum & arb & BR (endêmica): SE (MG) & ca,ce \\
\hline E. strictum & arb & $\mathrm{BR}$ (não endêmica): $\mathrm{CO}, \mathrm{SE}, \mathrm{S}$ & ce \\
\hline Galactia crassifólia & arb & BR (endêmica): NE, CO, SE & ca, ce \\
\hline G. grewiaefolia & arb & BR (endêmica): CO, SE (MG) & ce \\
\hline Harpalyce brasiliana & arb & BR (endêmica): N, NE, CO, SE & $\mathrm{a}, \mathrm{ce}$ \\
\hline
\end{tabular}


Tabela 1 (continuação)

\begin{tabular}{|c|c|c|c|}
\hline Espécie & Hábito & Distribuição geográfica & Domínio fitogeográfico \\
\hline Indigofera lespedezioides & arb & $\mathrm{BR}$ (não endêmica): $\mathrm{N}, \mathrm{NE}, \mathrm{CO}, \mathrm{SE}$ & $\mathrm{a}, \mathrm{ce}, \mathrm{ma}$ \\
\hline Leptolobium brachystachyum & $\operatorname{arv}$ & BR (endêmica): SE (MG) & ce (cr) \\
\hline L. dasycarpum & arv & $\mathrm{BR}$ (não endêmica): N, NE, CO, SE & a,ce \\
\hline Lonchocarpus costatus & arv & BR (endêmica): SE & ma,ce \\
\hline Lupinus parvifolius & arb & BR (endêmica): SE (MG) & ce (cr) \\
\hline Machaerium hirtum & arv & BR (não endêmica): N, NE, CO, SE, S & $\mathrm{a}, \mathrm{ca}, \mathrm{ce}, \mathrm{ma}, \mathrm{pt}$ \\
\hline M. stipitatum & $\operatorname{arv}$ & $\mathrm{BR}$ (não endêmica): NE, CO, SE, S & ce, ma \\
\hline Macroptilium bracteatum & arb & $\mathrm{BR}$ (não endêmica): N, NE, CO, SE, S & $\mathrm{ca}, \mathrm{ce}, \mathrm{ma}, \mathrm{pt}$ \\
\hline Myroxylon peruiferum & $\operatorname{arv}$ & $\mathrm{BR}$ (não endêmica): NE, CO, SE, S & ce,ma \\
\hline Oxyris monticola & arb & BR (endêmica): SE (MG) & ce,ma \\
\hline Periandra mediterranea & arb & $\mathrm{BR}$ (não endêmica): N, NE, CO, SE, S & $\mathrm{a}, \mathrm{ca}, \mathrm{ce}, \mathrm{ma}$ \\
\hline Platypodium elegans & arv & $\mathrm{BR}$ (não endêmica): N, NE, CO, SE, S & $\mathrm{a}, \mathrm{ca}, \mathrm{ce}, \mathrm{ma}$ \\
\hline Poiretia elegans & arb & BR (endêmica): SE (MG) & ce \\
\hline P. punctata & arb & BR (não endêmica): NE, CO, SE & $\mathrm{ca}, \mathrm{ce}, \mathrm{ma}$ \\
\hline Pterodon pubescens & $\operatorname{arv}$ & $\mathrm{BR}$ (não endêmica): N, NE, CO, SE & ce \\
\hline Rhynchosia edulis & arb & $\mathrm{BR}$ (não endêmica): NE, CO, SE, S & $\mathrm{ca}, \mathrm{ce}, \mathrm{ma}$ \\
\hline Sesbania exasperata & arb & BR (não endêmica): N, NE, CO, SE, S & $\mathrm{a}, \mathrm{ca}, \mathrm{ce}, \mathrm{ma}, \mathrm{p}$ \\
\hline Stylosanthes gracilis & arb & BR (não endêmica): N, NE, CO, SE, S & $\mathrm{a}, \mathrm{ca}, \mathrm{ce}, \mathrm{ma}, \mathrm{pt}$ \\
\hline S. guianensis & arb & BR (não endêmica): N, NE, CO, SE, S & $\mathrm{a}, \mathrm{ca}, \mathrm{ce}, \mathrm{ma}, \mathrm{pt}$ \\
\hline S. scabra & arb & $\mathrm{BR}$ (não endêmica): N, NE, CO, SE, S & $\mathrm{a}, \mathrm{ca}, \mathrm{ce}, \mathrm{ma}$ \\
\hline Swartzia macrostachya & $\operatorname{arv}$ & BR (endêmica): NE, CO, SE & $\mathrm{ca}, \mathrm{ce}, \mathrm{ma}$ \\
\hline S. pilulifera & arv & BR (endêmica): SE (MG), S & ce \\
\hline Vigna firmula & arb & $\mathrm{BR}$ (não endêmica): N, NE, CO, SE & $\mathrm{a}, \mathrm{ca}, \mathrm{ce}, \mathrm{ma}$ \\
\hline V. peduncularis & arb & $\mathrm{BR}$ (não endêmica): N, NE, CO, SE, S & ce \\
\hline Zornia curvata & arb & BR (não endêmica): N, NE, CO, SE, S & $\mathrm{a}, \mathrm{ca}, \mathrm{ce}, \mathrm{ma}, \mathrm{p}, \mathrm{pt}$ \\
\hline Z. latifolia & arb & $\mathrm{BR}$ (não endêmica): N, NE, CO, SE, S & $\mathrm{a}, \mathrm{ca}, \mathrm{ce}, \mathrm{ma}, \mathrm{p}, \mathrm{pt}$ \\
\hline Z. subsessilis & arb & BR (endêmica): SE (MG) & ce \\
\hline Z. villosa & arb & BR (não endêmica): CO, SE, S & ce \\
\hline
\end{tabular}

\section{Agradecimentos}

Ao Fundo de Amparo ao Ensino e à Pesquisa, pelo apoio financeiro e aos curadores dos herbários pelo envio de materiais.

\section{Literatura citada}

Alkmim, F.F. \& Martins Neto, M.A. 2001. A bacia intratectônica do São Francisco: Arcabouço estrutural e cenários evolutivos $I n$ : C. Piva-Pinto \& M.A. Martins-Neto (eds.). Bacia do São Francisco: Geologia e Recursos Naturais. Sociedade Brasileira de Geologia, Belo Horizonte, pp. 9-15.

Arroyo, M.T.K. 1976. The systematic of the legume genus Harpalyce (Leguminosae: Lotoideae). Memoirs of the New York Botanical Garden 26: 1-80.
Azevedo, A.M.G. 1981. O gênero Desmodium Desv. no Brasil: Considerações taxonômicas. Dissertação de Mestrado, Universidade Estadual de Campinas, Campinas.

Barbosa-Fevereiro, V.P.B. 1977. Centrosema (A.P. De Candolle) Bentham do Brasil - Leguminosae Faboideae. Rodriguésia 29: 159-219.

Batalha, M.A.P.L. 2001. Florística, espectro biológico e padrões fenológicos do Cerrado sensu lato no Parque Nacional das Emas (GO) e o componente herbáceosubarbustivo da Flora do Cerrado sensu lato. Tese de Doutorado, Universidade Estadual de Campinas, Campinas.

Burkart, A. 1971. El género Galactia (LeguminosaePhaseoleae) em Sudamérica com especial referencia a la Argentina y países vecinos. Darwiniana 16: 662-796. 
Carvalho-Okano, R.M. \& Leitão Filho, H.F. 1985. Revisão taxonômica do gênero Calopogonium Desv. (Leguminosae-Lotoideae) no Brasil. Revista Brasileira de Botânica 8: 31-45.

Costa, N.M.S. \& Ferreira M.B. 1982. O gênero Stylosanthes em Minas Gerais. Empresa de Pesquisa Agropecuária de Minas Gerais, Belo Horizonte.

Costa, L.C., Sartori, A.L.B. \& Pott, A. 2008. Estudo taxonômico de Stylosanthes (Leguminosae Papilionoideae - Dalbergieae) em Mato Grosso do Sul, Brasil. Rodriguésia 59: 547-572.

Drummond, G.M. (ed.) 2008. Lista vermelha das espécies da fauna e da flora ameaçadas de extinção em Minas Gerais. 2 ed. Fundação Biodiversitas, Belo Horizonte.

Eiten, G. 1972. The cerrado vegetation of Brazil. The Botanical Review 38: 201-341.

Eiten, G. 1983. Classificação da Vegetação do Brasil. Conselho Nacional de Pesquisa, Brasília.

Fernandes, A.G. 1996. Táxon Aeschynomene no Brasil. v.1, 1 ed. Editora da Universidade Federal do Ceará, Fortaleza.

Ferreira, M.B. \& Costa, N.M.S. 1979. O gênero Stylosanthes Sw. no Brasil. Empresa de Pesquisa Agropecuária de Minas Gerais, Belo Horizonte.

Fevereiro, V.P.B. 1987. Macroptilium (Benth.) Urb. do Brasil - Leguminosae - Faboideae - Phaseoleae Phaseolinae. Arquivos do Jardim Botânico do Rio de Janeiro 28: 109-180.

Flores A.S. 2004. Taxonomia, números taxonômicos e química de espécies de Crotalaria L. (LeguminosaePapilionoideae) no Brasil. Tese de Doutorado, Universidade Estadual de Campinas, Campinas.

Flores, A.S. \& Miotto S.T.S. 2001. O gênero Crotalaria L. (Leguminosae-Faboideae) na Região Sul do Brasil. Iheringia, série Botânica 55: 189-247.

Funch, L.S. \& Barroso, G.M. 1999. Revisão do gênero Periandra Mart. ex Benth. (LeguminosaePapilionoideae, Phaseoleae). Revista Brasileira de Botânica 22: 339-356.

Giulietti, A.M., Menezes, N.L., Pirani, J.R. Meguro, M. \& Wanderley, M.G.L. 1987. Flora da Serra do Cipó, Minas Gerais: Caracterização e lista de espécies. Boletim de Botânica da Universidade de São Paulo 9: 1-151.

Grear, J.W. 1970. A revision of the American species of Eriosema (Leguminosa-Lotoideae). Memoirs of the New York Botanical Garden 20: 1-97.

Grear, J.W. 1978. A revision of the new world species of Rhynchosia (Leguminosae-Faboideae). Memoirs of the New York botanical Garden 31: 1-168.

Harley, R.M. \& Simmons, N.A. 1986. Florula of Mucugê. Chapada Diamantina, Bahia, Brasil. Royal Botanic Gardens, Kew.
Hoehne, F.C. 1941. Leguminosas-Papilionadas: Gêneros Machaerium e Paramachaerium. Flora Brasílica. Instituto de Botânica, São Paulo, v.25, pp. 1-100.

Holmgren, P.K., Holmgren, N.H. \& Barnett, L.C. (eds.). 1990. Index Herbariorum - Part I: The Herbaria of the World. 8 ed. New York Botanical Garden, New York.

Köppen, W. 1931. Climatologia. Fondo de Cultura Económica, Buenos Aires.

Lewis, G.P. 1987. Legumes of Bahia. Royal Botanic Gardens, Kew.

Lewis, G.P. 1995. Leguminosae. In: B.L. Stannard (ed.). Flora do Pico das Almas. Chapada Diamantina, Bahia, Brasil. Royal Botanic Gardens, Kew, pp. 368-394.

Lewis, G.P. 1996. Apresentação. In: C.V. Mendonça Filho (ed.). Braúna, Angico, Jacarandá e outras Leguminosas da Mata Atlântica: Estação Biológica de Caratinga. Fundação Botânica Margaret Mee, Fundação Biodiversitas, Belo Horizonte.

Lewis, G.P. \& Owen, P.E. 1989. Legumes of the Ilha de Maracá. Royal Botanic Gardens, Kew.

Lewis, G.P., Schrire, B., Mackinder, B. \& Lock, M. (eds.). 2005. Legumes of the World. Royal Botanic Gardens, Kew.

Lima, H.C. 1985. Centrolobium Mart. ex Benth. (Leguminosae-Papilionoideae). Estudo taxonômico das espécies brasileiras extra-amazônicas. Arquivos do Jardim Botânico do Rio de Janeiro 27: 177-191.

Lista de Espécies da Flora do Brasil. 2013. Jardim Botânico do Rio de Janeiro. http://floradobrasil.jbrj. gov.br/2013 (acesso em 13.01.2013).

Mansano, V.F. 1997. Estudos taxonômicos da tribo Swartzieae (DC.) Benth. (Leguminosae-Papilionoideae) no Sudeste do Brasil. Disertação de Mestrado, Universidade Estadual de Campinas, Campinas.

Mansano, V.F. \& Tozzi, A.M.G.A. 1999. Distribuição geográfica, ambiente preferencial e centros de diversidade dos membros da tribo Swartzieae na região sudeste do Brasil. Revista Brasileira de Botânica 22: 249-257.

Mantovani, W. \& Martins, F.R. 1993. Florística do Cerrado na Reserva Biológica de Moji Guaçu, São Paulo. Acta Botanica Brasilica 7: 33-60.

Menezes, N.L. \& Giulietti, A.M. 1986. Campos Rupestres Paraíso Botânico na Serra do Cipó. Ciência Hoje 5: 38-44.

Miotto, S.T.S. 1987. Os gêneros Centrosema (DC.) Benth. e Clitoria L. (Leguminosae - Faboideae) no Rio Grande do Sul. Iheringia, série Botânica 36: 15-39.

Mohlenbrock, R.H. 1958. A monograph of the leguminous genus Zornia. Webbia 16: 1-141.

Monteiro, R. \& Gibbs, P.E. 1996. A taxonomic revision of the unifoliolate species of Lupinus (Leguminosae) in Brazil. Notes from the Royal Botanic Gardens Edinburgh 44: 71-104. 
Moreira, J.L.A. 1997. Estudo taxonômica da subtribo Phaseolinae Benth. (Leguminosae-Papilionoideae) no Sudeste e Centro-Oeste do Brasil. Disertação de Mestrado, Universidade Estadual de Campinas, Campinas.

Moreira, J.L.A. \& Azevedo-Tozzi, A.M.G. 1997. Indigofera L. (Leguminosae, Papilionoideae) no estado de São Paulo, Brasil. Revista Brasileira de Botânica 20: 97-117.

Munhoz, C.B.R. \& Proença, C.E.B. 1998. Composição florística do município de Alto Paraíso de Goiás na Chapada dos Veadeiros. Boletim do Herbário Ezechias Paulo Heringer 3: 102-105.

Neubert, E.E. \& Miotto, S.T.S. 1996. O gênero Lonchocarpus Kunth (Leguminosae-Faboideae) no Rio Grande do Sul. Iheringia, série Botânica 47: 73-102.

Patrus, M.L.R., Santos, A.C.S., Figueiredo, V.L.S., Matos, A.R. \& Menezes, I.C.R. 2001. Parcela mineira da bacia do São Francisco: Caracterização hidroclimática e avaliação dos recursos hídricos de superfície In: C. Piva-Pinto \& M.A. Martins Neto (eds.). Bacia do São Francisco: Geologia e recursos naturais. Sociedade Brasileira de Geologia, Belo Horizonte, pp. 285-326.

Pedersoli, J.L., Gavilanes, M.L., Ferreira, M.B. \& Camargos D'Assunção, W.R. 1976. O gênero Pterodon Vogel no Estado de Minas Gerais. Oréades 5: 1-17.

Perez, A.P.F. 2009. O gênero Zornia J.F. Gmel. (Leguminosae, Papilionoideae, Dalbergieae): revisão taxonômica das espécies ocorrentes no Brasil e filogenia. Tese de Doutorado, Universidade Estadual de Campinas, Campinas.

Pennington, T.D. 2003. Monograph of Andira (Leguminosae-Papilionoideae). Systematic Botany Monographs 67: 1-113.

Polhill, R.M. 1994. Classification of the Leguminosae In: F.A. Bisby, J. Buckingham \& J.B. Harborne (eds.). Phytochemical dictionary of the Leguminosae. v.1. Plants and their constituents. Cambridge University Press, Cambridge.

Polhill, R.M. \& Raven, P.H. (eds.). 1981. Advances in Legume Systematics. v.1. Royal Botanic Gardens, Kew.

Queiroz, L.P. 1999. Sistemática e filogenia do gênero Camptosema W.J. Hook. \& Arn. (Leguminosae: Papilionoideae: Phaseoleae. Tese de Doutorado, Universidade de São Paulo, São Paulo.
Queiroz, L.P. 2004. Flora de Grão-Mogol, Minas Gerais: Leguminosae. Boletim de Botânica da Universidade de São Paulo 22: 213-265.

Renger, F.E. \& Almeida-Abreu, P.A. 2000. The southern Espinhaço mountain range: its geodynamic evolution and diamond mineralization, Minas Gerais state, eastern Brazil: $31^{\text {st }}$ International Geological Congress - Rio de Janeiro- RJ. Post-congress field trip. Universidade Federal de Minas Gerais, Belo Horizonte.

Rodrigues, R.S. \& Tozzi, A.M.G.A. 2008. Reinstatement of the name Leptolobium Vogel (Leguminosae, Papilionoideae, Sophoreae). Taxon 57: 980-984.

Sartori, A.L.B. 2000. Revisão taxonômica e estudos morfológicos de Myrocarpus Allmão, Myroxylon L.f. e Myrospermum Jacq. (Leguminosae-PapilionoideaeSophoreae). Tese de Doutorado, Universidade Estadual de Campinas, Campinas.

Sartori, A.L.B. \& Azevedo-Tozzi, A.M.G.A. 1999. As espécies de Machaerium Pers. (Leguminosae: Papilionoideae: Dalbergieae) no Estado de São Paulo. Revista Brasileira de Botânica 21: 211-246.

Species link. 2012. Centro de Referência em Informação Ambiental \& Fundação de Amparo à Pesquisa do Estado de São Paulo. http://www.splink.cria.org.br (acesso em 14.01.2013).

Tozzi, A.M.G.A. 1989. Estudos taxonômicos dos gêneros Lonchocarpus Kunth e Deguelia Aubl. no Brasil. Tese de Doutorado, Universidade Estadual de Campinas, Campinas.

Warming, E. \& Ferri, M.G. 1973. Lagoa Santa e a vegetação dos Cerrados brasileiros. Itatiaia, Belo Horizonte.

Wojciechowski, M.F. 2003. Reconstructing the phylogeny of legumes (Leguminosae): an early $21^{\text {st }}$ century perpective. In: B. Klitgaard \& A. Bruneau (eds.). Advances in Legume Systematics. Part 10. Royal Botanic Gardens, Kew, pp. 5-35.

Viveiros, J.F.M. \& Walde, D. 1976. Geologia da Serra do Cabral, Minas Gerais, Brasil. Münsterische Forschungshefte Geologie und Palaeontologie 38: 15-27.

Zappi, D.C., Lucas, E., Stannard, B.L., Lughadha, E.N., Pirani, J.R., Queiroz, L.P., Atkins, S., Hind, D.J.N., Giulietti, A.M., Harley, R.M. \& Carvalho, A.M. 2003. Lista das plantas vasculares de Catolés, Chapada Diamantina, Bahia, Brasil. Boletim de Botânica da Universidade de São Paulo 21: 345-398. 